\title{
Símbolos unitarios en el tejido del Canzoniere de Petrarca. Las redes de los sonetos IV, LXII y CLXXXI. La petición de hilos del XL. Del soneto XXVI a la sextina doble
}

Recibido: 29/06/2012

Antonio ARMISÉN

Universidad de Zaragoza ${ }^{1}$

aarmisen@unizar.es

Revisado: $23 / 11 / 2012$

Aceptado: 04/12/2012

\section{RESUMEN}

Continuando trabajos anteriores centrados en la lectura numérica del Canzoniere, describo e interpreto su composición partiendo de la annominatio 'tesare/tessere', forma simbólica axial (menor) de la escritura del libro en cuanto textus. El soneto XL, integrado en la composición de los Rerum vulgarium fragmenta (Rvf) desde la supuesta forma o redazione Correggio (1356-1358), se confirma en el codice Vat. lat. 3195 como texto chiave de petición que declara la condición agustiniana armónica y unitaria de las autodenominadas rime sparse. La tradición anterior de la metáfora de la escritura como tessere (metafora di testo, poeta fabbro) ofrece una clave de lectura que ayuda a entender el Canzoniere, modelado biográfica y formalmente con el referente del poeta enamorado, prefigurado (figurae) por el providencial nacimiento de Laura y la rete de Giovanni et Piero (soneto IV), más tarde cantor y prisionero de amenazadoras reti (sonetos LXII, CLXXXI y otros), después condenado en su propio laberinto (soneto CCXI). Son 'vincula amorosi' y/o motivos unitarios que, apoyados por la lectura numérica que estudio, se resuelven finalmente, hemos de pensar, como símbolos de redención. Sostienen este trabajo el reconocimiento de algunos antecedentes y el de sus perceptibles secuelas en la literatura castellana de los siglos XVI y XVII.

Palabras clave: Composición, annominatio, red, laberinto, textus.

\section{Unifying symbols in the tissue of Petrarch's Canzoniere. \\ The nets of sonnets IV, LXII and CLXXXI.}

Sonnet XL's petition of strings. From sonnet XXVI to the double sestina

\section{ABSTRACT}

A continuation of previous writings dealing with the numerical composition of the Canzoniere, this paper describes and interprets the annominatio 'tesare/tessere', an axial (mi-

\footnotetext{
${ }^{1}$ Departamento de Filología Española (Literatura). Facultad de Filosofía y Letras, Universidad de Zaragoza, C/ Pedro Cerbuna, 12 (50009).
} 
nor) symbolic form in the book's writing as textus. Sonetto XL, integrated in the composition of Rerum vulgarium fragmenta (Rvf) from the alleged forma or redazione Correggio (1356-1358), is confirmed in Codex Vat. Lat. 3195 as a key petitional text which reveals the harmonic and unitary Augustinian nature of the self-styled rime sparse. The previous tradition of the metaphor of writing as tessere (metafora di testo, poeta fabbro) offers an interpretive key which helps to understand the Canzoniere, formally modelled with reference to the poet in love or prefigured (figurae) by Laura's providential birth and the rete di Giovanni et Piero (sonetto IV), then becoming a prisoner of menacing reti (sonetti LXII, CLXXXI and others), and later on condemned to his own labyrinth (sonetto CCXI). These are 'vincula amorosi' and/or unitary motifs which, one must conclude, should be interpreted, relying on the numerical reading studied here, as symbols of salvation. This interpretation is supported through the identification of some antecedents, and of the sequels traceable in 16th and 17th-century Castilian literature.

Keywords: Composition, net, labyrinth, textus, poet as weaver.

SUMARIO: 1. Consideraciones previas. La red evangélica del soneto IV y las redes del poeta desde el soneto "Padre del ciel" de la prima preghiera. 2. La metafora di testo de Gorni. Amore y Morte en la petición del soneto XL. 'Textus', reti, tela di ragna y laberinto. 3. El 153 de Agustín y el poeta textor: del soneto XXVI a la sextina doble CCCXXXII. El comentario de Vellutello sobre el soneto XL y la tradición agustina. Los hilos y el robo del laberinto en la poesía de Lope de Vega. 4. Entre los Psalmos y las nugae de Catulo. El epilion LXIV y sus ecos. Sobre la conocida huella de Agustín y las lecturas del Canzoniere. 5. Los hilos del soneto XL, clave de la lectura macrotextual de Michelangelo Picone. De posiciones y forma grafico-visiva. El tessere en la poesía de Sannazaro y Garcilaso.

\section{CONSIDERACIONES PREVIAS. LA RED EVANGÉLICA DEL SONETO IV Y LAS REDES DEL POETA DESDE EL SONETO "PADRE DEL CIEL" DE LA PRIMA PREGHIERA}

La composición del Canzoniere que estudio desde hace años nace de una concepción teórica religiosa y teológica del numerus que, al parecer, como hemos visto en anteriores trabajos, tiene precedentes por evaluar en los De musica libri VI, en el In Iohannis evangelium y en otros tratados de Agustín. Si bien la reconocemos posicionalmente modulada en los Rerum vulgarium fragmenta (en adelante $R v f$ ) con la narración secuencial de una historia amorosa, espiritual y biográfica, tras el dispar modelo o referente conocido de las Confessiones, su lectura asume hoy la consecuente condición de una búsqueda formal inacabada, tentativa y plural.

La forma temporal básica de la autobiografía (tiempos de las distintas experiencias y tiempo o tiempos de la escritura) presenta posibilidades y soluciones varias que la sucesión de fragmenta o pezzi, ajustados por sistemas cronológicos, secuen- 
cias narrativas a reconocer por el lector, o también la simple sucesión en el continuum (ordo) convierten en significativas (Soldani 2007a: 330).

Será así oportuno señalar, valorar y estudiar los temas dominantes, los motivos recurrentes con sus variaciones y formas repetidas en la composición de los 366 pezzi. Percibir que no trabajamos una secuencia narrativa única es fácil. Más difícil parece aceptar que la sucesiva superposición e imbricación de los componentes de ese continuum nos sitúa reiteradamente ante formas numéricas que podrían o pueden ser intencionales y significativas; pero que, como tantas veces ocurre, resultan en más de una ocasión solo un espejismo, la reflejada proyección del sistema de búsqueda y de lectura. Otras, sin embargo, han sido construidas con intención evidente, destinadas a la atención de lectores que las reconozcan.

El presente trabajo ejemplifica la plural posibilidad, esos peligros y nuestras dudas últimas en casos que he seleccionado porque, con la condición de metáforas del texto que estudio, aparte sus particulares y diferenciadas implicaciones genéticas y semánticas, son también confirmación acorde de la reconocible huella de Agustín. Resultado ahora de una revisión de la metáfora centrada por el textor-tessere-textus con numerosos antecedentes de obligada valoración (Viljamaa 2007: 131-138), apuntada en trabajos anteriores, tras la descripción de formas de composición documentadas y verificables de los $R v f$, permiten plantear la posibilidad de otros casos arriesgados, más aventurados o menos fiables, sin abandonar el problema de la escritura poética y las formas de composición textual.

Señalé en el 2004 la relación temática de los símbolos venatorios o piscatorios con la forma numérica y el significado redentoristas que pautan la composición de los $R v f$ (Armisén 2004a). Los 'vincula amorosi' (lacci, nodi), mencionados en el Africa y evaluados en el Secretum (II, [80]), comentados recientemente por Chessa (2005), ofrecen evidencia consistente del interés de esos motivos descriptivos del Canzoniere, acompañados por su sentido espiritual e introducidos desde «tolse Giovanni da la rete et Piero», v. 7 del soneto IV que cierra el fol. 1, recto del codice autorizado (Petrarca ed. diplomática 2004c: 227); pero después activos en la composición figurada del libro y la localización de contrastes calculados, posiciones marcadas.

La incidencia en el codice Vat. Lat. 3195 de los textos del fol.1, recto y en particular de los sonetos III y IV con el componente redentorista y unitario de las rime sparse es perceptible. La cesura semántica que tras el soneto LX y desde los sonetos LXI-LXII establece con las preghiere del undécimo aniversario la macrosecuencia de il riscatto de 306 pezzi $(17 \times 17+17)$ no puede ahora ser ignorada. Lo he apuntado reiteradamente en trabajos anteriores (cf. Armisén 2004a: 83-84 y 94-96; y con más datos en 2008: 56-67).

Si bien el caso conocido del rinnovato proemio (Amaturo [1971] 1988: 281) y la prima preghiera del soneto LXII, vv. 5-8, comentada por Santagata (Petrarca ed. 2004b: 317-320), dada la relevancia compositiva, temática y posicional del soneto "Padre del ciel, dopo i perduti giorni", merece todavía nuestra atención inicial: 
piacciati omai, col Tuo lume, ch'io torni

ad altra vita et a più belle imprese,

sì ch'avendo le reti indarno tese

il mio duro adversario se ne scorni.

Ante todo, destacaré la red tendida por Amor del soneto CLXXXI (forma di Giovanni [1366-1367]) que enredó en el laurel al poeta enamorado. Porque Amor hila, teje y tiende o monta también lazos y redes, como el soneto CXCVIII, vv. 1-4, ayuda pronto a comprobar: «L'aura soave al sole spiega et vibra / l'auro ch'Amor di sua man fila et tesse»; y como el juicio último de la canción CCCLX, v. 50 permite finalmente recordar con la evocación de su peregrinatio y las menzogne de «Il mio adversario» del v. 76. Tender y tensar o tejer son verbos que en la lengua poética de Petrarca (tesare / tessere) merecen particular atención, vinculados como veremos en textus, texto y macrotexto por una dilatada, sostenida annominatio. Señalaré su interés simbólico axial en los temas del poeta prisionero cantor (Philomela [y sus hilos], con la silenciosa denuncia de la tela narrativa enviada a Progne, que Fernando de Herrera evocará después en ocasiones varias desde su soneto XXVIII "Süave Filomela que tu llanto") y de il poeta fabbro (o Dédalo arquitecto, condenado en su propio laberinto: soneto CCXI, v. 14).

Años más tarde Garcilaso dirá «De los cabellos de oro fue tejida la red / que fabricó mi sentimiento, / do mi razón revuelta y enredada» (Canción IV, vv. 101106); y la traducción publicada por Garcés en 1591 del soneto CLXXXI se inicia con «Una red el Amor tendido había / de perlas de oro toda entretexida». Una traducción duplicada y particular del soneto CLXXXI que Antonio Prieto (Petrarca ed. 1985: 134), señalando el "precedente" del toledano, anota brevemente con razón. Annominatio focalizada que en los $R v f$ sostiene la vigencia activa interrelacionada del tesare / tessere en textos y lecturas pertinentes. La traducción de Cortines en 1989 ("Amor tejió en la hierba una red bella") y después la de Crespo en 1995 ("Amor tejió una red encantadora") nos lo confirman radicalmente todavía, ciertamente de forma algo más confusa.

Pensemos también por un momento en "Vago augelletto che cantando vai" y en "Deh porgi mano a l'affannato ingegno", sonetos 365 y 364 que desde la versión Pm4 (1369-1372?) cerraban in ordine y tono umile el ms. Vat lat. 3195 (Stierle 1996: 239 y 241-242; Soldani 2007b: 769 ss.). Como en trabajos anteriores, uso numeración arábiga en cursiva para dar cuenta de la posición original de los textos, que han sido reordenados por las postille marginales del codice d'autore. (Cf. Santagata en Petrarca ed. 2004b: Tavola II, p. ccxii).

Así, los motivos del soneto CLXXXI tienen destacado interés compositivo y reaparecerán después. Es texto importante, como vemos, integrado en el proyecto del codice desde fecha anterior a 1366 o muy poco después que no hemos de olvidar: 


\begin{abstract}
Amor fra l'erbe una leggiadra rete d'oro et di perle tese sott'un ramo dell'arbor sempre verde ch'i' tant'amo, benché n'abbia ombre più triste che liete.

L'ésca fu 'l seme ch'egli sparge et miete, dolce et acerbo, ch'i' pavento et bramo; le note non fur mai, dal dì ch'Adamo aperse gli occhi, sì soavi et quete.

E 'l chiaro lume che sparir fa 'l sole folgorava d'intorno; e 'l fune avolto era a la man ch' avorio et neve avanza.

Così caddi a la rete, et qui m'àn colto gli atti vaghi et l'angeliche parole, e 'l piacer e 'l desire et la speranza.
\end{abstract}

Un texto conocido cuya «leggiadra rete» los editores modernos ponen en relación directa reiterada con «le reti» anteriores de famoso "Padre del ciel". Señalaré aquí dos hechos relevantes, de interés macrotextual simbólico potenciado si tomamos en consideración las implicaciones del nacimiento de Laura, la rete evangélica y la pesca milagrosa en el soneto IV de las rime sparse.

El primer detalle que habrá que valorar será el perceptible contraste significativo que la rete evangélica de los vv. 7-8 en el redentorista soneto IV, señalando la condición figurada de Laura desde su nacimiento como ayuda divina, tiene pronto con las amenazadoras reti del rinnovato proemio, soneto LXII, vv. 7-8.

El segundo es, tal vez, una confirmación funcional del mencionado contraste en términos de composición: la posición del soneto CLXXXI, casualmente o no, dista 119 posiciones (o 17x7) del soneto LXII, de la oración cristiana en cuyo v. 7 he localizado el amenazador reconocimiento en sí mismo de «le reti indarno tese, / il mio duro adversario se ne scorni», v. 8. Una lectura formal en la que veladamente, pronto y de nuevo, la composición numérica, quizá, se convierte en forma constitutiva de la secuencia marcada por la petición, iniciada ahí.

Son, en principio, redes tendidas, descritas como peligros espirituales en que Francesco se enreda a sí mismo. Amenazas que pretende superar, sortear con la ayuda divina que solicita en el soneto LXII. Recordemos también el antecedente de otras sonoras reti que enredaron al propio Agustín en Confessiones, X, 33, 49-50. Un problema directamente relacionado en los $R v f$ con la prima preghiera del enamorado que fundará en "Padre del ciel" tras la desesperada maldición del LX y desde el soneto LXI el deseado inicio de su recuperación.

Si la pauta formal cifrada con el 17 de Agustín fuese en esta ocasión intencional, tras las peticiones del LXII, el soneto CLXXXI marcaría después, señalaría posi- 
cional y simbólicamente la «leggiadra rete [...] dell'arbor sempre verde ch'i' tant'amo» caracterizándola ya con un componente contrastivo, positivo/negativo, semivelado, que la figura de Laura, instrumento de redención apuntado con el soneto IV de la primera rete, la Providentia Divina y la transformación espiritual del enamorado resolverán más adelante.

La confirmación de esa posibilidad formal no es concluyente, parece difícil de alcanzar. Sin otros datos, sería muy aventurado suponer que la relación de los sonetos LXII y CLXXXI deba leerse así en términos numéricos necesariamente. Como veremos más adelante, creo que es en ese contexto creciente, contrastivo y simbólico, de amenazadoras redes iniciales, tendidas y enredadas, introducidas por la sagrada y apostólica del soneto IV, en el que se integra con la mención inicial de providentia, donde leeremos mejor la petición textual del soneto XL.

Con razón, podemos también señalar el contraste perceptible entre la descripción negativa de las amenazadoras reti del soneto LXII, relacionadas por destacados lectores con el pecado y lo demoníaco -en el juicio último de la canción CCCLX, «mio adversario» será solo referido a Amor-, y la descripción final, benéfica y positiva de Laura en los tercetos del soneto CLXXXI que desde el v. 1 ofrece en su primer cuarteto otra descripción de la red tesa por Amor bajo el árbol dáfneo. La referencia a la capacidad de Laura de "sparir fa '1 sole» podría recordarnos también el comienzo de la storia: «Era il giorno ch'al sol si scoloraro / per la pietà del suo factore i rai» y el soneto III referido al viernes santo del primer encuentro.

Después, la inmediata descripción de los poderes de Laura que le retienen con propiedad son una medida declaración de relación con lo divino y de su condición salvífica: «et qui m'an colto / gli atti vaghi et l'angeliche parole, / e 'l piacer e 'l desire et la speranza», vv. 12-14. Una "Allegoria piacevole dell' innamoramento» de acuerdo con las anotaciones de Carducci y Ferrari (Petrarca ed. 1899: 266-267), en la que, tras el v. 5 «L'ésca fu 'l seme», Moschetti y Santagata (Petrarca ed. 2004b: 804-805, nn. al v. 1 ss.) describen a Laura como richiamo o cebo de Amor (uccellatore, según Castelvetro; Petrarca ed. 2005: 837-840, nn. v. 1 ss.).

Esa descripción final hace pensar también, más adelante, en las gratie del soneto CCXIII que cierran significativamente, en posición marcada con perspectivismo temporal-personal en texto y codice, los primeros 153 pezzi de la macrosecuencia de il riscatto (LXI-CCCLXVI). Los ecos de la breve descripción de la amada del soneto CLXXXI en otras loas posteriores ayudan a valorar su ubicación.

Sobre la posición y condición funcional de "Padre del ciel" he dicho ya bastante. Solo cabe ahora repasar los componentes que establecen su relación con el CLXXXI. El soneto LXII es texto marcado por una doble petición: la conocida de sus vv. 5-8 referida a las reti de su culpa y su caída; y después el primer miserere de los vv. 12-14, que, tras el reconocible contraste con esa primera rete evangélica del soneto IV («tolse Giovanni da la rete et Piero»), se cierra «ramenta lor come oggi fusti in croce», confirmando la condición de undécimo aniversario mediante la referencia redentorista del sagrado viernes santo, ade- 
lantada en el mencionado soneto III (Pastore Stocchi 1981: 171-191; Stroppa 2004: 164189). No faltan indicios de obligada lectura intertextual.

Si en el soneto CLXXXI el arbor inicial de la leggiadra rete se asimila en los cuartetos a la tentación adánica, al árbol del bien y del mal y a la caída, el «Così caddi a la rete» de su último terceto, guarda probablemente (con la cifra numérica posicional implícita en el soneto) la clave espiritual de la descripción de su amada, su sentido funcional y último positivo. Reconocer la creciente cristianización del árbol laureano, precedida por la rete del soneto IV, pero marcada después por las redes culpables del undécimo aniversario, las citadas preghiere y con ellas la explícita referencia de la croce que cierra el soneto LXII, simbolizan el proceso de recuperación iniciado tras la maldición del soneto LX (Armisén 2008: 52 ss.)

El lector atento reconocerá que tanto el motivo del poeta enamorado, víctima de las redes tendidas por Amor en torno al laurel (Amor uccellatore ${ }^{2}$ ), después interlocutor propio y final del ave canora enamorada (prisionera) en el Canzoniere, como el modélico caso adánico tienen ecos en textos de valor posicional, realzados en principio por la transcripción autógrafa in ordine.

Recordemos también que en su espositione, reimpresa y brevemente ampliada en 1538 sobre el soneto CCLXXI -cuya posición clave comento en otro lugar (Armisén, en prensa-a y b) - Vellutello lee el soneto "L'ardente nodo ov'io fui d'ora in hora" como referido a la capacidad alcanzada por Francesco para superar la nueva tentación amorosa en términos proverbiales: «ma nuova rete vecchio uccel non prende» (Petrarca ed. 1538: 114, recto). Desde luego, el comentarista y reordenador del libro de Petrarca permanece ajeno a la composición posicional, que rechaza al negar el ordo autorizado.

El interés del modelo adánico y el símbolo del pájaro cantor amenazado o pri-

\footnotetext{
${ }^{2}$ Comenzaré con una nota cervantina, solución literaria y casi final de algunas referencias quijotescas anteriores a la poesía de Petrarca. Un tema lírico conocido (Amor uccellatore) que Petrarca desarrolla y potencia. Reaparece todavía, años después de la explícita traducción de Garcés (Madrid, 1591), integrado con humor en la novela del XVII castellano. Lo encontramos acompañado de los comentarios sobre las redes («en cerrada selva» y «redes de hilo verde [...] de durísimo diamante o más fuertes») en las que don Quijote, explicando a Sancho su rechazo de Altisidora y las distintas formas de hermosura, quedará literalmente enredado (Quijote II, cap. LVIII). Si el caballero culpa a «los encantadores que me persiguen», la 'zagala' cortesana explica que solo «para nuestro pasatiempo ahí están tendidas». Lo considero desenlace irónico o sarcástico, y solución narrativa de Miguel de Cervantes con final paródico, a la pretendida condición firme del hidalgo como caballero enamorado constante, en relación anterior con versos horacianos muy conocidos e imitados del Canzoniere (soneto CXLV, "Ponmi ove 'l sole occide i fiori et l'erba"); en cualquier circunstancia "cocido o asado» (Quijote, II, XLIIII). El tema del soneto CLXXXI y las reti amorosas de los Rvf proveen pretexto famoso, un referente complementario reconocible en contexto acorde. Se integra con verosímil realismo en la tradición lírica, dramática, y cortesana rural de la fingida Arcadia que Cervantes trata con humor, tras diversas quijotescas opiniones sobre famosos e imitados, gastados versos de Petrarca, en su revisión social y crítica (Petrarca, Garcilaso, Camoes) de la cultura literaria castellana en 1615 (Armisén 2010a: 43-45 y 60).
} 
sionero lo confirman todavía los sonetos 365 "Vago augelletto", vv. 1 ss. (cod. Vat. lat. 3195 [Petrarca ed. 2004c], fol. 71, recto) y 364 "Deh porgi mano", vv. 12-14 (Vat. lat. 3195, fol. 71, recto) del cierre in ordine, que hoy reconocemos mejor en su función posicional. No podemos ignorar su devaluativa reordenación propuesta por las postille, como CCCLIII y CCCLIV. (Stierle 1996: 242 ss.; Soldani 2007b: 769798). El modelo redentorista agustiniano dominante en la lectura hoy aceptada impone o conlleva el triunfo del pentimento y, en mi opinión, refuerza o apoya la velada huella (numérica) de la acción de Providentia.

Pero ambas lecturas del códice sostienen la valoración macrotextual alternativa con los mismos números. Ampliando ahora y corrigiendo el marco de referencias propuesto por Soldani en el 2007, el soneto CLXXXI adelantaba con propiedad posicional y adecuación temática perceptibles la relevancia del símbolo arbóreo en la forma in ordine, impresa en 1501 y hoy preterida. La señalan con sus motivos coincidentes: el poeta enamorado como uccello y augelletto, prisionero y cantor; el árbol láureo y la caída adánica, e incluso «le angeliche parole», v. 13 de la descriptio de Laura (Soldani 2007b: 770). La distancia que separa hoy en la versión ortodoxa los textos señalados está próxima al 170, aunque no coincida con esa cifra, fijando en esos dos textos el cierre de lo que se describe vagamente como galassia ornitologica y la referencia precisa que hay que computar.

Como distintos estudiosos señalan (Quaglio 1973, Pasquini 1985, Stierle 1996), la reordenación de los 31 componentes finales preserva relaciones internas de los grupos textuales que reubica. Conocer la composición de las formas potenciadas nos ayudará a comprender sus razones.

Si bien las últimas posiciones del ordo transcrito de los sonetos 364 y 365 podrían haber sido pronto ajustadas en el proyecto macroestructural inicial, las dos opciones del codice d'autore permiten verificar posibilidades alternativas o casi semejantes de un mismo modelo de composición. Stierle (1996) mantiene que los cambios posicionales reducen la melancolía en un momento final en que Petrarca prefiere destacar el componente de la esperanza que precede con el CCCLXV a "Vergine bella". El soneto CCCLXIV -v. 9 «pentito et tristo de' miei sì spesi anni»-, con una revisión cronológica final de la storia, 153 pezzi después del CCXI de la data sacra del primer encuentro, ofrece hoy otra clave demarcativa o liminar y otra razón temática y formal importante que valorar (Armisén 2011: 33 ss.)

Volviendo atrás con intención, en una posición que tampoco debemos olvidar, con el soneto XXVI, v. 9 ss. («Et tutti voi ch'Amor laudate in rima / al buon testor degli amorosi detti / rendete honor»), Petrarca concibe o insinúa una interesante identificación etimológica y metafórica (metonimia/sinécdoque) de Amor (antes soneto $\mathrm{V}$, vv. 1-2) y del poeta enamorado, vástago en peligro y brote de la tradición de poesía amorosa, de la religio amoris -en esta ocasión identificado con algún poeta amigo, recipiendario, quizá, del soneto anterior- en cuanto testor (lat. textor; cast. tejedor) según Leopardi [1826] (Petrarca, ed. 2003: 74): tessitore. Cioè scrittore (Petrarca ed.1899: 36; y Petrarca ed. 2004 b: 135, n. 10): 
Più di me lieta non si vede a terra nave da l'onde combattuta et vinta, quando la gente di pietà depinta su per la riva a ringratiar s'atterra;

né lieto più del carcer si diserra chi 'ntorno al collo ebbe la corda avinta, di me, veggendo quella spada scinta che fece al segnor mio sì lunga guerra.

Et tutti voi ch'Amor laudate in rima, al buon testor degli amorosi detti rendete honor, ch'era smarrito in prima:

ché più Gloria è nel regno degli electi d'un spirito converso, et più s'estima, che di novantanove altri perfecti.

Es una identificación (testor / tessitore / tessere) de perceptible base etimológica con numerosos antecedentes ${ }^{3}$, confirmada más tarde en otros textos como el soneto XL con referencia al propio poeta, que reaparecerá referida a Amor con el recuerdo de la conocida annominatio ([tesare] / testor, tessere) en el soneto CLXXXI. Aquí presentada con el antecedente evangélico del hijo pródigo recuperado y la creciente pretensión, declarada repetidamente después, de elevar la condición de su escritura poética amorosa al terreno de lo espiritual. Sobre la plural lectura de los vv. 7-8 del XXVI, v. Petrarca (ed. 1899: 36)

Como el marino en peligro o el condenado finalmente redimido se aferran a una última esperanza, el poeta se ve ahí sostenido por Amor, que inscribió en su corazón el aún velado nombre de su amada en el inicial soneto $\mathrm{V}$; motivado por ese amor culpable revisado en el Secretum que en los $R v f$ parece pronto, desde la primera página (fol. 1, recto), destinado a salvarle de males y culpas mayores.

Boscán, con la conocida mediación del Cant I de Ausias March, reescribirá con

\footnotetext{
${ }^{3}$ Alan Deyermond (1999: 71-104) ofreció una interdisciplinar y documentada revisión del tema del tejido en el texto en las conocidas chansons de toile de los siglos XII y XIII o en lo que denomina "poemas análogos". El profesor británico partía del ejemplo de Penélope y Ulises en la Odisea y del tejido de María en la Anunciación del Liber Jacobi o Protevangelium (imagen ésta documentada en la iconografía desde el s. V y regular hasta el s. XIII que ha sido relacionada con Exodus 35: 36-37). Acorde con su omisión del léxico y textos italianos, no considera su presencia en los $R v f$ ni en sus precedentes bíblicos y latinos. Semejan carencias y errores que precisan corrección en lo referido a la metáfora textil. Véase lo que dice sobre textus, término usado en el s. VIII, y sobre alguno de los términos pertinentes en pp. $71 \mathrm{ss}$. Hoy debemos adelantar mucho esas fechas, de acuerdo con las observaciones de Toivo Viljamaa (2007: 131-138). Agradezco la noticia del trabajo de Viljamaa y la consecuente localización del término textus en Virgilio a mi colega y amigo Ángel Escobar.
} 
intención los motivos de los cuartetos del XXVI de Petrarca en sus sonetos CVII [79] y CVIII [80] (Armisén 1982: 398-400). El barcelonés desde el soneto CV [77] de 1543 seriaba una cadena de símiles que, si ha de recordarnos (siquiera funcionalmente, en términos literarios) los phantasmae de Agustín y de Petrarca, queda explícita y directamente relacionada con los sueños. Dará forma como secuencia de imágenes a la búsqueda literaria de comprensión, expresión poética y mejor solución para sus errores y males. El reconocimiento que Boscán hace en su última canción CXXX [102] de 153 versos de la final utilidad de su amor (similia similibus curantur), no carece de antecedentes en los $R v f$.

\section{LA METAFORA DI TESTO DE GORNI. AMORE Y MORTE EN LA PETICIÓN DEL SONETO XL. 'TEXTUS', RETI, TELA DI RAGNA Y LABERINTO}

Volvamos al texto del Canzoniere culminado en 1374. Después del soneto XXVI, el soneto XL formalizaba, cardinal petición de ayuda in ordine, la reaparición de un tema simbólico anterior conocido con la metáfora alegórica de la tela que teje el poeta. Una situación presentada ante el lector del libro, en ese momento de escritura. Pide la ayuda generosa que necesita, los hilos necesarios para la obra en curso: la escritura, la creación poética, el estilo literario y la composición de los Rerum vulgarium fragmenta. El lector interesado en la aventura espiritual narrada tuvo que entenderlo así. Petrarca no era, no pudo ser ajeno a esa lectura directa y contextual.

Centrémonos en el discutido y epigramático soneto XL "S'Amore o Morte non dà qualche stroppio", trabajado enigma de lectura plural que ha planteado numerosos problemas. Texto temprano -fechado por Billanovich y Santagata en 1338 o 1339 (Santagata 1988: 60 ss.; 1990: 359; y en su ed. de Petrarca [1996: 219] 2004b: 220 ss.)- cuya inclusión en la hipotética redazione Correggio (1356-1358) lo situaba ya en la misma posición relativa in ordine que le confiere después desde 1366 la transcripción de Malpaghini. De alguna manera, su integración funcional en los $R v f$ puede estar ya influido por su conocimiento de Catulo, asunto importante sin huella todavía en la biografía de Ugo Dotti (1987) donde nada se dice aún sobre la primera lectura del veronés. Contrástese después con la revisión del biglietto poetico en la edición de Dotti del Canzoniere (Petrarca 2004a [1996]: 130-131). La relación de Petrarca con la poesía de Catulo nos interesa ahora.

Valorando la imagen metaliteraria de la obra tejida y sus hilos, quizá motivado tras la lectura del poeta veronés -fechada por Billanovich en 1345-, con su integración activa (metaliteraria) en la estructura compositiva del Canzoniere, Petrarca convierte el soneto XL en texto cardinal simbólico de relevante interés. Centra y permite verificar en el libro el uso y función de una conocida metáfora de la escritura y de la vida que el poeta de Arezzo sitúa con potenciada intención en los Rvf. Marco Fabio Quintiliano (Institutio oratoria, IX, iv, 13: «verba eadem qua compo- 
sitione vel in textu iungantur vel in fine claudantur») trata del textus al desarrollar sus comentarios sobre la necesaria composición de la obra (Oxford Latin Dictionary (ed. 1990: 1935, s.v. textus, 3); Crespo 2001: 568; Viljamaa 2007: 131 ss.). La tradición simbólica del tejido textual confirma su relación con los problemas de la composición en una obra de retórica fundamental. La versión latina original lo prueba mejor que alguna de sus traducciones modernas. Según el estudio de Viljamaa (2007), no es el único caso que habría que valorar.

Si el antecedente de los lamentos del órfico ruiseñor «quaerens populea maerens philomela sub umbra» en el final de Georgicas (IV, vv. 511 ss.), símbolo del poeta, ha de recordarse, y si su relación con la silenciosa tela tejida por Philomela y enviada a Progne (Metamorfosis, VI, vv. 422-674) no puede ahora olvidarse, otros precedentes bíblicos, clásicos e incluso próximos en poesía de lengua vulgar son reconocibles para el lector interesado, como es verificable la presencia sostenida, anterior y posterior, de la metáfora del tessere en la sucesión de textos in ordine de Petrarca. Realizan simbólicamente el problema de la escritura poética y su lectura.

La supuesta incorporación en la llamada forma o redazione Correggio parece confirmar que el soneto XL se incorpora como parte simbólica activa en un proyecto formal en progresión, complejo y calculado de fecha anterior, aunque su ajuste último y más completo sea tardío. Depende de la finalización del programa.
S'Amore o Morte non dà qualche stroppio a la tela novella ch'ora ordisco, et s'io mi svolvo dal tenace visco, mentre che l'un coll'altro vero accoppio,
i farò forse un mio valor sì doppio tra lo stil de' moderni e '1 sermón prisco, che, paventosamente a dir lo ardisco, infin a Roma n'udirai lo scoppio.
Ma però che mi manca a fornir l'opra alquanto da le fila benedette ch'avanzaro a quel mio dilecto padre
perché tien' verso me le man' sì strette, contra tua usanza? I prego che tu l'opra, et vedrai riuscir cose leggiadre.

Contrástese, en todo caso, con la reciente edición de Savoca (Petrarca ed. 2008a: 71) que corrige el texto del terceto final, eliminando la interrogación, y entiende también que el texto en preparación debía ser De viris illustribus. 
No es ese tampoco el problema de lectura que ahora me interesa más. Con esa transcripción en la posición 40 de los $R v f^{4}$, concebidos en términos de composición antes de 1366 como proyecto, quizá, muy semejante a la realización de 1374, el poeta asumía con ventaja la función contextual y nuevas lecturas del soneto de petición en la ordenación acabada. Son, pues, semejantes o los mismos hilos con los que tanto Amor tirano como el poeta enamorado tejen, desarrollan y completan sus vínculos mediante la integración operativa y el recuerdo simbólico de la redentorista red del soneto IV, más adelante la ragnatela («di dolce et d'amar pieno [...] opra d'aragna») del CLXXIII y el mítico laberinto en que concluye el CCXI. La transcripción desde 1366 no era mera compilación ${ }^{5}$.

Todo hace pensar que Petrarca podía, tal vez, incluso reconocer el tema del tessere, el motivo del textus en particular, en una comparación descriptiva de la Eneida (Libro V, vv. 588-591) referida al laberinto de Creta: «ut quondam Creta fertur Labyrinthus in alta / parietibus textum caecis iter anticipitemque / mile viis habuisse dolum, qua signa sequendi / falleret indeprensus et inremeabilis error» (Virgilio ed. 1996: Lib. V, vv. 588-591). Tampoco es caso único en el poema. El famoso tema de la descripción del escudo de Eneas, profética obra divina trabajada por Vulcano, ofrece otro ejemplo destacado en Lib. VIII, v. 625: «hastamque et clipei non enarrabile textum».

El continuum de los $R v f$ nos advierte repetida y simbólicamente sobre los problemas de la escritura y la composición en relación con el tessere, en coincidencia con un destacado pasaje sobre la composición de Quintiliano (IX, iv, 13) que, recogido y

\footnotetext{
${ }^{4}$ Será obligado considerar la adecuación de la posición 40 y sus posibles implicaciones. Conocemos el interés biográfico de ese año, lo que no reduce la atención de Petrarca hacia esa cifra, ni limita su valor numérico. Es número relacionado con los significados fundamentales del 4 (armonía, amistad...) y el 10 (plenitud, totalidad...). Valorando la función simbólica del soneto XL en los $R v f$, puede recordarnos la lectura pitagórica propuesta por Amadi en 1563 sobre el soneto IV que completa $(1+2+3+4)$ el fol. $1, r$. del codice autorizado. Foster Hopper (1978 [1938]: 44 ss.) considera el 40 un glorified tetraktys, según propuestas de Plutarco -en un epítome desconocido para Petrarca- sobre De animae procreatione in Timeo: es resultado de sumar el producto de la multiplicación por 4 de los cuatro primeros números $(4+8+12+16$; según Plutarco). E iniciando el cómputo, tras los cuatro proemiales del fol 1 recto, con el soneto $\mathrm{V}$ del nombre de Laura, el 36 es el primer número cuadrangular (6x6) y rectangular (9x4) (v. Armisén 1982: 424 ss.; y 2008: 59-60 nn. 6 y 7). Era información numérica accesible. El autor del epítome de Plutarco no era el único en conocer los datos aritméticos que repaso ahora.

${ }^{5} \mathrm{Si}$ iniciamos el cómputo en los $R v f$ desde el soneto $\mathrm{V}$-lo que nos llevó en 2008 a localizar la ratio sesquitertia (4/3) con precisión centesimal en la data sacra-, el soneto XL sería el 36 in ordine (o $\left.6^{2}\right)$. El 6 es también el primer número perfecto (De civitate Dei, XI, 30). Casualmente o no, son cifras pertinentes, conocidas y cuya difusión no dependía de la recuperación de Plutarco. Expresan y potencian la búsqueda de composición unitaria y armónica. Macrobio no dice nada sobre el 40, pero sí sobre el 4 y el 10, sobre el 7 y el 8 o la tetraktýs pitagórica (Comm. In Somnium, I, 34-47; y De musica, I, v. Correa 2009: 94-98) Sobre la relación del 1, el 4 y el 10 con la modulatio y la armonia (De musica, lib. I; v. Correa Pabón 2009: 66-71). En la tradición medieval sincrética, cf. Røstvig (1970: 38 ss.; 47-48, 55, 59 y otros); también la documentada síntesis de José Oroz (1975: 427-453).
} 
valorado en el Oxford Latin Dictionary (ed. 1990: 1935, s. v. textor, textum, textus), ha estudiado en el 2007 Viljamaa, interesado en sus secuelas.

Petrarca manejaba sus hilos, amenazado y dolorido por la culpa y el tiempo que se escapa, temas de Augustinus en el Secretum, pero con la intención de un poeta lírico narrador, poeta fabbro que trabaja sus versos, la fabrica del Canzoniere y el encaje de la escritura y de sus símbolos sobre un patrón y un programa previos. La aparición circunstancial del tessere en otras ocasiones como los sonetos del «L'aura» (CXCVIII, v. 2 «l'auro ch'Amor di sua man fila et tesse») o el soneto CCI «Mia ventura et Amor m'avean sì adorno / d'un bello aurato et serico trapunto» que, en el umbral previo al fol. 40, concluye el tríptico de la «bella man» e «il guanto», requiere ya otro momento y nuevo espacio. La labor y prenda añorada, el bordado guante de Laura, podría haberse situado, engastada con intención (ratio sesquitertia) en una sección de 306 componentes que ahora consideramos en relación con el tessere y la escritura.

Con lo dicho acerca de la annominatio ornitológica apuntada y el fundamento etimológico de la metáfora que nos ocupa, inexcusable en este caso, tomaré como punto de partida la sugerente y documentada revisión del tessere como metafora di testo en el soneto XL y otras obras poéticas publicadas por Gorni (1993 [1979]: 137-152). Bettarini percibe la identificación del poeta con Amor y su escritura (Petrarca ed. 2005: 14731474 , nota al v. 48). Interesado en esa presencia repetida en los Rvf, Corrado Bologna (2007: 194), valorando la lectura macrotextual, lo considera prueba de volontà di dire; $\mathrm{y}$, tras el soneto XXVI, v. 10, entiende que en la sextina doble (CCCXXXII, vv. 46-47) el propio poeta se autodefine como tessitore dei pensieri in parole. Por el contrario, Dotti anota en 1996 y 2004, sin margen de duda, que el sujeto de «tessea in rime» es Amor (Petrarca ed. 2004a: 881, n. 47).

Interesante anfibología poética que, con su provocadora ambigüedad carga y cierra la estrofa octava de la última sextina CCCXXXII. Tiene antecedentes reconocibles en el libro de poesía vulgar referidos a la misma metáfora tessere. Apoyada por la annominatio y la metaliteraria metafora di testo, en términos intertextuales o macrotextuales, desde luego, viene de lejos.

Como hemos visto con el texto del Secretum (III, 138: «Equidem necessario eventura sunt»; v. Armisén, en prensa-b; cf. aquí n. 15), el uso de la profecía y la ambigüedad intencional no es ajeno a la escritura de Petrarca. Su presencia en el caso de los versos que nos ocupan la confirman esas varias lecturas; y la respetan (o descuidan e ignoran), las más importantes y mejores traducciones castellanas: Garcés (1591), Cortines (1989), Crespo (1995).

Así mismo, parece intencional porque Petrarca la sitúa en una posición destacada de la sextina doble, que creo ha sido pautada y marcada por el módulo de 17 en relación con la macrosecuencia de il riscatto (LXI-CCCLXVI [153+153]: Armisén, en prensa-a); y, quizá también, por el tema del estilo y la escritura poética del textor que el soneto XXVI introducía 306 pezzi antes de la mencionada sextina. 
Comentamos una interesante recurrencia macrotextual, conocida hoy por muchos lectores atentos, aunque ajenos a la cifra de Agustín. Repasar ahora las anotaciones modernas, que en algún caso advierten el tema en Dante (Petrarca ed. 1899: 36, n. al v. 10; 463-464 n. al v. 47; después Petrarca ed. 2004b: 135, n. 10 y 13021303, nn. 39 y 47-51; Petrarca ed. 2004a: 75 y 881; o Petrarca ed. 2005: 135-136, nn. 9-10, y 1473-1475, nn. 42-55), no puede llevarnos a la simplista, errónea conclusión de que su reconocimiento es solo muy tardío. La escritura de Petrarca en las rime sparse se construye reiteradamente con este tipo de recurrencias, conocidas como propias de la forma canzoniere por anotadores y lectores desde fecha temprana. Las razones y opiniones que apoyan la hipótesis de que la sextina in morte ocupa una posición intencional y significativa son varias.

Reconociendo el sentido y valorando el alcance de la relación con textos anteriores evocados, dada la relevancia de temas marcados por las repetidas palabras de rima, la importancia de la acción dominante de Morte no puede ignorarse en la excepcional sextina doble $(6 \times 12=72[+3])$, ni en su octava estrofa. Morte, última palabra de rima en la primera (lieto, notti, stile, rime, pianto, morte), tras la paradójica afirmación del soneto CCCXXVII, v. 7, reaparece como annominatio textual incuestionable («Morte m'à morto»), reiterada como elemento constitutivo, intensificada tras su inmediata posición final en la stanza séptima («né contra Morte spero altro che Morte», v. 42), desde la palabra inicial del primer verso de la stanza octava (Frasca 1992: 231) -en esta ocasión principio y fin de prolungata annominatio-, de nuevo como palabra de rima, vv. 43-48:

Morte m'à morto, et sola pò far Morte ch'i' torni a riveder quel viso lieto che piacer mi facea i sospiri e 'l pianto, l'aura dolce et la pioggia a le mie notti, quando i penseri electi tessea in rime, Amor alzando il mio debile stile.

Y recordando esa primera aparición de la metáfora textil en el soneto XXVI, v. 10 , hemos de advertir necesariamente que, casualmente o no, la medida distancia que lo separa de la única y original sextina doble coincide de nuevo con el 306 (o 153x2), forma cifrada por el pensamiento de Agustín, que he descrito repetidamente en otros casos como $17 \times 18$. Tal vez no sea el caso verificable más perceptible o evidente de esa forma simbólica, pero difícilmente podremos considerarlo como casual o insignificante, conocido lo que ya sabemos sobre el 153 y el 17 desde mis trabajos de 2004 y 2008. No es tampoco la primera recurrencia simbólica medida con el 153 de los Rvf. La operatividad funcional de la metafora di testo del soneto XL se refuerza, si valorásemos la distancia entre el soneto XXVI y la CCCXXXII que, con el motivo recurrente, centran la atención sobre la escritura poética. 
La annominatio es forma propia y reiterada -en la lengua poética, fundacional base de retrogradatio y retrogradatio cruciata-, figura elocutionis característica de la sextina que ha sido objeto de atención en el Canzoniere ${ }^{6}$. Como Frasca (1992: 17) advierte, la sextina doble, última y única in morte, se construye con «vere e proprie parole isotopiche». Sus palabras de rima son términos recurrentes de interés sostenido en el libro ${ }^{7}$. Sobre la presencia del 6, el 12 y el 72 en la sextina y en el codice Vat. lat. 3195 he tratado en estudios anteriores (Armisén 2011: 11 ss.)

La condición de su poesía tejida quedaba marcada por Muerte y por la acción de Amor, textor inicial (soneto V, vv. 1 ss.) y capaz en el pasado de elevar su estilo. El poeta necesitará, desde el soneto XL, tras el "Mia ventura et Amor" del CCI y después todavía en la sextina doble in morte otra ayuda más poderosa que aquella "Mia benigna fortuna" de otro tiempo, si pretende mejorar todavía su obra, abocada ahora a su final ya próximo. Algunas recurrencias resultan significativas.

Cualquiera que fuese el motivo original o la causa del soneto XL, no creo que, en esta ocasión, deba ya pensarse solo en la construcción de textos por completo ajenos a la recollectio y formalización agustiniana de su poesía amorosa. Si bien determinar qué texto de Agustín solicitaba en 1338 o 1339 puede ser una especulación tal vez verosímil, aunque difícilmente verificable, leer después el soneto XL, transcrito in ordine como provocación textual dirigida finalmente al lector de las rime sparse, sí parece oportuno.

Centrándonos en los problemas que nos ocupan, importa la reaparición de la metafora di testo etimológica (textor, tessere), apoyada con la paronomasia y la annominatio que las sextinas intensifican, sosteniendo y desarrollando motivos reconocibles. Ha sido integrada en los $R v f$ con atención a la vivencia biográfica, y queda

${ }^{6}$ La sextina de Petrarca, según Frasca (1992: 208 ss.) es «un voler possedere, e far giostrare, le res attraverso la costante riarmonizzazione dei verba». La elección de las palabras de rima de una sextina tiene interés, como los poetas modernos que la han practicado saben bien. La recuperación moderna de la sextina nos sitúa con J. Gil de Biedma en los problemas de lectura funcional de la forma orgánica y la forma abstracta, comentados por Herbert Read en 1932. Cf. Armisén (1999: 43-46, 71-72, n. 32 y 154-155).

${ }^{7}$ Pelosini (1998: 665) considera que «La duplice legge dell' 'identità' e della 'variazione' cui tale forma poetica, più di ogni altra, sembra soggiacere iuxta propria principia (parole-rima e retrogradatio cruciata) viene applicata da Petrarca ai nove componimenti del suo Libro in virtù del loro novo istituto di genere [...] sistema coerente e autonomo nel quale, come è sembrato, l'ordine delle sestine nel Libro riflette momenti redazionali e/o revisionali cronológicamente successivi $[\ldots]$ sistema che intreccia $[\ldots]$ sottili relazioni, formali e tematiche, con il sistema più ampio del Canzoniere, in cui lo stesso sistemasestine è accolto» (Pelosini 1998: 666-667, texto y n. 6). No es muy diferente la opinión de Berra (1991: 219-220) cuando, partiendo de palabras de Teodato Osio sobre la sextina (L'armonia del nudo parlare con ragione di numeri pitagorici, Milan, 1637) trata la relación entre recurrencia formal, retrogradatio cruciata y expresión del dolor en las primeras líneas de su trabajo sobre la sextina doble. La importancia de la annominatio en la lengua poética de los $R v f$ es hoy fácil de reconocer, aunque Massimo Zenari (2001), paradójica y erróneamente (en mi opinión), elude y excluye sin excepción los interesantes casos (regulares y también supernumerarios) de las 9 sextinas de Petrarca en su extenso trabajo de clasificación tipológica. 
localizada en la CCCXXXII con intención, apoyada por la composición posicional modular (Armisén 2011: 23; y en prensa-a), confirmando su coherencia narrativa en el desarrollo de la storia (Hernández Esteban [1987] 2001: 170 ss.; Berra 1991: 232; y Frasca 1992: 207-258). Berra (1991: 226 y 231) advierte que

il tema del desiderio di morte si articola in cinque motivi distribuiti regolarmente nelle strofe, che, pur replicando diversi spunti della prima parte, ne eludono l'ossessivo tautologismo [...] L'iterazione perseguita in tutti gli aspetti del testo ha come effetto globale un dettato eccezionalmente ricco di echi interni [...] Questo inestricable reticolo di conessione ne esaspera la ripetività della sestina

El tejido del texto no es un motivo temático que deba considerarse ajeno a otros desarrollados por poetas petrarquistas que como Sannazaro, el Garcilaso todavía napolitano de la Égloga III dedicada a Don Pedro de Toledo o el tardío Lope de Vega de las Rimas lo trabajan con otros intereses, muchos años después. Relacionar la égloga en octavas reales con el carmen LXIV de Catulo solo nos lo confirma.

La metáfora alegórica del tessere y sus hilos, con antecedentes en la iconografía de tema evangélico, tenía presencia situacional y temática repetida confirmada en la tradición de la lírica francesa medieval (Zink 1978: 3-24; y textos 77-79, 96-97, 102) y en otros textos análogos o siquiera próximos de varias lenguas. Tampoco el tejido y los hilos de la escritura son ajenos a las artes amorosas femeninas en ejercicios poéticos castellanos del XV, recogidos en el Cancionero General de 1511, según Morros (Garcilaso de la Vega ed. 1995: 9). No se trata, pues, de una situación poética o una imagen de la escritura rara o desconocida, ni antes ni después de Petrarca.

\section{EL 153 DE AGUSTÍN Y EL POETA TEXTOR: DEL SONETO XXVI A LA SEXTINA DOBLE CCCXXXII. EL COMENTARIO DE VELLUTELLO SOBRE EL SONETO XL Y LA TRADICIÓN AGUSTINA. LOS HILOS Y EL ROBO DEL LABERINTO EN LA POESÍA DE LOPE DE VEGA}

Cabe considerar con algún fundamento la posibilidad de que la recurrente cifra de Agustín, en este caso, tenga vinculación con la metáfora que nos ocupa; e incluso que el ajuste posicional de los textos que comento (XXVI-CCCXXXII) sea concebido en fase avanzada de la transcripción del libro que se cierra en 1374, dada la importancia que el estilo y la lengua poética tienen en la sextina in morte incorporada en $\mathrm{Pm}$. 3 desde 1369 (Petrarca ed. 2004b: ccviii- ccxi y 1298; Berra 1991: 221 ss.).

La petición de hilos de "S'Amore o Morte non dà qualche stroppio" en el soneto XL resuena armónica y reverbera potenciada por la lectura de Vellutello desde 1525 
-él mismo ajeno al ordo- y por la traducción castellana de Enrique Garcés ${ }^{8}$. El referente de Agustín quedaba generalmente reconocido y las notas de Leopardi al soneto nos lo confirman en 1826 (Petrarca ed. 2003: 90-91).

De hecho, el estudio del P. Pedro Martínez Vélez (1931: 22-23) sobre el numerus en el pensamiento filosófico de Agustín se cierra todavía con la imagen del hilo, el ovillo y la madeja. Puede que sea imagen destacada en algún texto de Agustín (que no localizo), pero difícilmente será solo casual coincidencia ajena a los antecedentes que reconozco en el mencionado soneto XL de Petrarca, texto de interés particular entre los miembros de la Orden de San Agustín, fundada, como es sabido, por Inocencio IV en 1244 con comunidades religiosas de la Toscana.

Menos puede ya extrañarnos que el tema de los hilos, el tejido y la urdimbre reaparezca de nuevo ${ }^{9}$, fugazmente, cuando Correa Pabón (2009: 178-179) comenta la analogía de la luz y el sonido de Agustín (ed. 1988: VI, 13, 37-38): «In his ergo cum appetimus convenientia pro naturae nostro modo, et inconvenientia respui$m u s »$. Sus antecedentes bíblicos vagos podrían, quizá, localizarse en palabras de Moisés (Exodus 35, 36-37). Reiterándola como metáfora textil del Creador, esos motivos reaparecen en el Viejo Testamento integrados en algunas versiones de los Salmos (Psalmus CXVIII; v. nn. 18 y 19 más abajo).

Si, como Vitruvio (Armisén 2008: 56 ss. y n. 3) o Macrobio (ed. 2001: 1xxi), y con ellos Petrarca, Agustín conocía la condición del 6 en cuanto número perfecto, saber que el hiponense describe el 12, de acuerdo con la suma de sus factores, en cuanto número pluscuamperfecto, como documenta Pedro Martínez Vélez O.S.A. (1931: 22, n. 1) parece oportuno. (De civitate Dei: XI, c. 30; De Genesi ad litteram libri XII, IV, c. 2; y también Oroz 1975: 430-435) El trabajo del religioso agustino, alegando interés exclusivo en el pensamiento filosófico de su santo Patrón, eludirá

\footnotetext{
${ }^{8}$ La traducción publicada por Enrique Garcés en 1591 (Petrarca ed. 1985) es en esta ocasión muy libre («Mas fáltame del hilo que ha sobrado / a ti, dilecto padre mío, Augustino, / al urdir de tus telas soberanas» XL, vv. 9-11). Después de Vellutello, el reconocimiento de Agustín en el soneto XL parece de aceptación general. (Petrarca ed. 1989: 62). La traducción de Garcés alcanzó amplia difusión durante siglos. Contrástese, tras los trabajos de Foresti (1921), con las opiniones de Billanovich y los comentarios y anotaciones posteriores de Santagata (Petrarca ed. 2004b: 220 y 223), Dotti (Petrarca ed. 2004a: 131) y Bettarini (Petrarca ed. 2005: 217 ss.). La «tela novella ch'ora ordisco», aquí y aho$r a$, puede muy bien ser (solo, en ese contexto; o siquiera también, tras la recuperación arqueológica del soneto en su función original) la tejida por Petrarca con «le fila benedette» de Agustín en los Rvf. Malpaghini lo transcribe como último soneto del fol. 9 verso. Coincidiendo con Picone $(2004,2007)$, creo que el interés del soneto XL -como, en mi opinión, ocurre en el caso del soneto CCLXVI, cierre in vita que he comentado en Armisén (2011: 26-31)- viene determinado, con su transcripción in ordi$n e$, por la conocida lectura final, contextual y prevalente.

${ }^{9}$ Deyermond (1999: 76-77) advierte que la metáfora del tejido, relacionada con les travaux de toi$l e$, es forma simbólica de la escritura o composición poética con antecedentes. Los reconoce indirectamente, a través de Dutton, en la muwashshaha del siglo X -nombre derivado de wishah: cinturón tejido con una colección de temas sucesivos-. Son temas comentados antes por Bec (1977: vol. I, 116118). Véase también mi n. 12.
} 
toda referencia a las conocidas exégesis numéricas bíblicas sobre los Salmos y el Evangelio de Juan, pero hace una aproximación útil tanto a la concepción filosófica y teológica del numerus como al análisis numérico de Agustín sobre la música y la poesía latina en De musica libri VI, De ordine o De Trinitate.

Los estudios de Luque (2001 y Agustín ed. 2008), Otaola y Correa permiten hoy entender mejor la coherencia compositiva neopitagórica y modular de la influencia literaria espiritual y teológica de Agustín en Petrarca, reconocida ya como huella de Confessiones, pero con probables o presumibles antecedentes también en el libro VI de los De musica (Agustín ed. 2008: 25). La reciente tesis de Correa Pabón plantea en 2009 directamente la relación de Agustín con Vitruvio y sus propuestas sobre el modulus (v. Armisén 2008: 56 ss. y n. 3; en prensa-a). No dudo de que muchos de los «fila benedette» (soneto XL), hilos así mismo necesarios para la construcción del Secretum, y los Rvf procedan in origine, directa o indirectamente, de los De musica libri VI y de Confessiones (Armisén, en prensa-a). La insistencia de Petrarca en algunas formas y motivos o su consistente tratamiento en los Rvf parecen apoyar la oportunidad de valorar los libros I y VI del tratado de Agustín sobre rítmica y música (scientia bene modulandi).

El artículo de Berra sobre la sextina CCCXXXII incide repetidamente en el componente numérico del hapax formal. Y el trabajo de M. S. Sapegno (1999: 42 ss. y 72-82) ofrece observaciones sobre el estilo y su repetida mención en los $R v f$ referidas a numerosos textos -apenas esbozadas sobre el soneto XL, pero algo más atentas respecto a la sextina doble-.

Después nos interesan el comentario y notas de la edición de Bettarini (Petrarca ed. 2005: 216-218). La profesora de Florencia valora tanto el origen y (presumible) función primera del soneto epistolar como otras huellas léxicas que ayudarán a reconocer y leer su integración textual activa, definitiva y funcional en los $R v f$. Como he señalado, los 366 pezzi quedaban desde el soneto IV que cierra el fol. 1 recto cifrados por la red redentorista y serán después, en el sonetto CCXI del fol. 42 recto, propuestos como laberinto. Tras ese soneto IV y el fol. 1 recto, considerando su relevancia temática, posicional, funcional, leo los sonetos $\mathrm{V}$ y CCXI desde el fol. 1 verso en cuanto simbólicos componentes demarcativo inicial y nodal de la forma unitaria ratio sesquitertia de los 362 restantes, transcritos en los 72 folios numerados del codice d'autore (Armisén 2008: 58 ss.).

Lope de Vega, interesado como poeta amoroso y satírico ocasionalmente en la metáfora textil (soneto 152, Rimas [1602]), aunque con una comprensión dispar del motivo y el tema, solo circunstancial o incompleta de la forma del Canzoniere, vuelve con presumible intención a la metáfora sostenida que nos ocupa y a sus símbolos cardinales en algún texto relevante. Lo hace con la memoria del hilo de Ariadna, antes cristianizada ya por Petrarca -como nuevo Teseo y nuevo Garcilaso-, mediante la evocación de "Sì è debile il filo a cui s'attene / la gravosa mia vita», canción XXXVII, v. 1 ss.; y con el recuerdo vivo de la búsqueda espiritual del poeta toscano. Lope de Vega inicia sus Rimas sacras de 1614 en el soneto I "Cuando me 
paro a contemplar mi estado" con el mismo mito del laberinto que el Canzoniere presentó en el último verso del soneto chiave CCXI, tras la data sacra (Armisén 1982: 341-344 y 359-378). Señalaré, pues, que no era esa tampoco la primera vez que lo trataba con presumible intención en un cuidado soneto inicial.

Así, el soneto I del fénix de los ingenios en 1602 presentaba ya la imagen del texto, de sus versos pretenciosos con «hurtáis el laberinto a Creta» en cuanto robo literario con antecedentes del poeta madrileño. La traducción por Hernández de Velasco en 1555 (Virgilio ed. 1982) de la descripción comparativa de la Eneida (Libro V, vv. 587 ss.) no recoge menciones del étimo de textum, aunque si la referencia a su relación con la trabajada composición («intrincada fábrica»): «laberinto oscuro, / cuya confusa e intrincada fábrica / con mil caminos, calles y senderos / la gente confundía y engañaba». La traducción de Echave-Sustaeta (Virgilio ed. 1992: p. 286) es mucho más útil o explícita ahora en lo referido al textum virgiliano: «tenía el Laberinto un pasadizo entretejido de paredes ciegas, / y una equívoca trampa con sus mil direcciones». La estrecha relación del Laberinto del CCXI, chiave de la ratio sesquitertia de los $R v f$ y su "compositio calendariale" con el tessere y la fábrica del libro de Petrarca tiene antecedentes y posibles ecos.

Y doce años más tarde, tras la muerte de su hijo Carlos Félix y la de Juana Guardo, las Rimas sacras de Lope de Vega se abren en 1614 con reconocibles componentes simbólicos del Canzoniere («Entré por laberinto tan estraño, / fiando al débil hilo de mi vida», soneto I, vv. 9 ss.), texto inicial que, en la rica tradición formal petrarquista (Herrera, Elegía IV, 25 ss.; Canción IV, 92 ss.), con la reutilización del conocido símbolo clásico, marca el componente espiritual dominante de su crisis personal y religiosa en esa nueva entrega. Lope de Vega conocía tanto el texto original del Canzoniere de Petrarca como su traducción e imitaciones, pero las diferencias de composición de sus dos colecciones de rimas con los $R v f$ y con los canzonieri de Sannazaro o Boscán y Herrera son evidentes. No es momento para detenernos en ellas.

En 1613 Quevedo en su Heráclito cristiano, con otras referencias a cebos y lazos, hacía mención de las redes en su Salmo IX («Cuando me vuelvo atrás a ver los años / que han nevado la edad florida mía, / cuando miro las redes, los engaños / donde me vi algún día», vv. 1 ss.) y en el que, posiblemente, junto a la huella de Horacio o Catulo, reconocemos el eco de Petrarca (soneto CCCXV) y de Garcilaso. En Quevedo (ed. 1981), comentando sus naufragios morales, encontramos las redes en la canción "El escarmiento", vv. 33-42 (Las tres musas, 176). Usa el verbo devanar («Devanan sol y luna, noche y día», v. 9) en algún soneto (El Parnaso español, 99); o tal vez se refiere al hilo de la vida en el famoso "Cómo de entre mis manos te resbalas" (El Parnaso, 78a) y cierra con el hilar de la Parca otro: "Arroja las balanzas, sacra Astrea" (El Parnaso, 53b). Son ejemplos y símbolos frecuentes en textos morales. 


\section{ENTRE LOS PSALMOS Y LAS NUGAE DE CATULO. EL EPILION LXIV Y SUS ECOS. SOBRE LA CONOCIDA HUELLA DE AGUSTÍN Y LAS LECTURAS DEL CANZONIERE}

Lo que sabemos hoy sobre la escritura del codice Vat. lat. 3195 no es poco. Al menos permite concluir que Petrarca era muy consciente de la operación textual que la transcripción in ordine y sus correcciones traían consigo. El caso del soneto $\mathrm{XL}$ y su activación posicional y contextual no es único en los $R v f$, incluso si nos limitásemos a los textos dirigidos de una u otra forma a los Colonna (Armisén 2011: 27 ss.) Y si Petrarca podía conocer, con las opiniones de Agustín sobre la cifra numérica de los Salmos, las referencias de la Biblia y en particular las ocasionales de los Salmos a la Creación, obra tejida por la mano divina (PS. CXVIII; cf. n. 19 más abajo), tenía ante sí otros antecedentes clásicos de esa alegoría metafórica como los casos próximos de Catulo y Ovidio permiten verificar.

El interés del poeta veronés en la composición de los $R v f$ no se acaba con la forma del recuperado liber y sus nugae. En relación con el tema del tessere y los hilos, atención particular merece su extenso carmen LXIV ("Peliaco quondam prognatae vertice pinus"). Si atendemos a la posibilidad de una lectura simbólica como imagen activa y cardinal de la tela y los hilos del soneto XL, apoyada por la recollectio del codice de Petrarca, relacionada después mediante la transcripción in ordine con el laqueus y las simbólicas redes, será importante revisar la incidencia de su conocimiento y lectura del liber de Catulo en Verona (el perdido Codex Veronensis Catullus), indicialmente fechada por Billanovich en $1345^{10}$. Si bien la primera redacción del soneto XL parece anterior, su posterior integración operativa en los $R v f$ como forma simbólica sostenida, asumida y potenciada en la sextina CCCXXXII, v. 47, se produce después, cuando el interés del poeta en los textos de Catulo es una realidad.

El epilion LXIV del veronés se convierte en un precedente simbólico de alcance con dilatada huella y ecos múltiples, dada la presencia, sostenida como descriptio, del tema de la colcha y sus hilos. Un importante correlato objetivo visual interpolado, cuadro dentro del cuadro y forma cornice que recoge el caso de Ariadna y el cortejo de Baco, integrados en el tema de la boda de Tetis y Peleo.

Tras la introducción directa de la écfrasis (vv. 50-51), declarada después (vv. 265 ss.) y con presencia sostenida, se narra el tejer de las Parcas (vv. 303-322). El motivo telar reaparece vinculado al Destino desde el v. 323; y como bordón final, referido al discurso y al hilo de la vida unificando y potenciando sus efectos. Leit-

${ }^{10}$ V. Billanovich (1996: 458 y nn. 206 y 207). También Santagata (Petrarca ed. 2004b: cix); contrastar con su comentario a la sextina XXII (Petrarca ed. 2004b: 88 ss.). Es la primera sextina, de fechación discutida, y texto que ocupa una posición coincidente con la edad de Francesco en el primer encuentro con Laura, el 6 de abril de 1327. El verso 17 expresa la maldición del día de su nacimiento al amor: «et maledico il dì ch'i' vidi 'l sole», Petrarca (ed. 2004b: 91 y n. 17). 
motiv de cierre que acompaña la profecía sobre Aquiles de las Parcas que tejen con el hilo de sus ruecas y husos (vv. 303-323), «aeternumque manus carpebant rite laborem», v. 310. Será también un verso recurrente, repetido hasta doce veces: «currite ducentes subtegmina, currite, fusi» ${ }^{11}$.

Un poema clásico y un episodio famosos, con huellas en las virgilianas quejas de Dido - de donde en la traducción castellana en endecasílabos sin rima de la Eneida de Hernández de Velasco lo toman Cervantes y Altisidora en 1615 (Armisén 2010a: 17 ss., 27 ss.) - y también con secuelas conocidas en Ovidio (Metamorfosis, Heroidas, Ars amatoria).

Muchos años antes del lienzo mitológico de "Las hilanderas" (circa 1657), obra de Diego Velázquez, encontramos el motivo de las artes femeninas desarrollado mediante una hiperbólica, comparación del propio Lope de Vega con Hércules, dominado por ellas en el soneto "Hermosa Parca, blandamente fiera", titulado $A$ una dama que hilaba ${ }^{12}$. A la luz de la información actual, es texto que puede suscitar comentario, siquiera por contraste.

La dama del soneto 152 de las Rimas (1602), «dueña del hilo de mi corta vida» parece capaz de tejerle ropa -de hacerle un traje, diríamos hoy-, de vestir al mismísimo y desnudo Amor con sus manos. Ha sido descrita inicial, discretamente, como mujer «blandamente fiera». Y algo creía saber Lope sobre las artes femeninas. Ma-

${ }^{11}$ El procedimiento tiene ecos perceptibles en el repetido diez veces «salid sin duelo lágrimas corriendo» del parlamento de Salicio en la Égloga I de Garcilaso. En 1615, Altisidora se presenta como doncella enamorada con un romance acompañado por música de harpa (Quijote, II, XLIIII). El caballero contestará después en II, XLVI con idéntica rima, criticando la ociosidad como causa de desvaríos femeniles, que pueden corregirse con el coser y el bordar («Suele el coser y el labrar»), antídoto conocido que tal vez trastoca. Don Quijote cantará a Dulcinea en términos de pintura indeleble (Quijote II, XLVI). Las labores blancas recomendadas serán después recordadas como terapia en las críticas finales del caballero ante la duquesa a esas peligrosas aficiones literarias (Quijote II, LXX). En un desigual trabajo sobre la metáfora textil en la novela cervantina, Patricia Crespo (2001: 567 ss.) descuida el tema y la figura de la doncella de los Duques, aunque recoge ya información varia sobre el texere. Altisidora parece conocedora de la Eneida, buena lectora de Garcilaso, experta en libros de caballerías, diestra en labores de costura, maestra en el uso de esa forma de estribillo (Quijote II, LVII; v. Armisén 2010: 18 ss. y 50-51). Una fórmula clásica que refuerza el componente rítmico unitario y la cohesión en momentos relevantes de textos extensos. Enigmático y consciente de sus antecedentes clásicos, vuelve con fuerza en la poesía moderna con el repetido nevermore de Edgar Allan Poe en The raven, texto y forma comentados por su autor con ironía en The philosophy of composition. Lo creo un eco tardío del cras, cras latino de los córvidos, forma presente en sonetos de Lope de Vega.

${ }^{12}$ Lope de Vega, manteniendo el tema del hilo de la vida, en esta ocasión la suya propia, juega con patetismo verista y conciencia crítica medida, acorde con la tradición medieval y renacentista que convertía a Hércules, héroe domeñado y transformado por las artes femeninas, en mera hilandera. Con el ejemplo de las Parcas, introducía el culto tema mítico inicial, pero el oxímoron del verso inicial, el difuso referente personal de «dueño», v. 2 -quizá el Amor, mencionado solo en el v. 7- o ahí la referencia clave con antecedentes reconocibles «de cuya tela, Amor, de oro tejida / si no fuera desnudo se vistiera» y los tercetos llevan a pensar que, muy probablemente, se trata de un soneto de queja sobre dependencias amorosas, de una sátira a persona. Un soneto que con doble sentido y humor, mediante la hipérbole hercúlea cuestiona, satírico y crítico, a la dama. 
rino vuelve después sobre los temas y motivos del soneto de Lope que imita, según apuntó Dámaso Alonso (1972: 768-769) recogiendo observaciones muy anteriores de Meninni (1667) y Menghini (1888).

Pero el soneto XL de Petrarca no trataba los mismos asuntos. No lo hace tampoco con la misma intención. De hecho, con su integración definitiva en los $R v f$, vendrá a contrastar con el uso contextual anterior del tessere referido a Amor, a la escritura y la poesía de la religio amoris, uso introducido en el codice Vat. Lat. 3195 por el soneto XXVI. El XL es ahí, ante todo, un texto de petición que, eludiendo los problemas de su fechación original, interpreto en la lectura final y directa como función prevalente, potenciada con su inclusión en el codice d'autore, ajustada con el total de los 366 pezzi en el año 70 del poeta o muy poco antes.

Hoy parece fácil reconocer que el soneto XL "S'Amore o Morte", desde su inclusión en los $R v f$, invocó pronto y en posición medida «a quel mio dilecto padre», v. 11 -según muchos lectores del siglo XVI y la traducción castellana de 1591, el propio Agustín (véase mi n. 8)- ofrecía un reconocimiento general e inexcusable, avalado por Vellutello (Petrarca ed. 1525: 195, recto y verso). Un biglietto de fecha temprana e imprecisa con el que pedía ayuda a un amigo o mecenas de Roma para entretejer trama e hilo de su opra (desde la transcripción y difusión del Canzoniere, para muchos lectores, esas nuevas nugae en las que lo leerán).Y también prometía maravillas («et vedrai riuscir cose leggiadre»), con un tejido textual todavía hoy insatisfactoriamente resuelto.

Textos, años y crisis después de su primera redacción, lo encontramos en los $R v f$ bajo poderes aún amenazadores: «S'Amore o Morte non dà qualche stroppio / a la tela novella ch'ora ordisco». Comentando las sextinas de Petrarca, Frasca (1992: 353 ss.) documenta la presencia casi regular de Morte entre las palabras de rima, y adelanta la reiteración dominante de los tempi commentativi sobre los tempi narrativi en las sextinas posteriores a Petrarca.

El soneto XL es texto metaliterario, centrado en la actividad creadora del poeta (poeta fabbro) con una imagen conocida. Al menos en las rime sparse, reconocible variatio del anterior in ordine "Sì è debile il filo a cui s'attene" de la canción XXXVII, tampoco incluida en la prima raccolta di servizio (Pr; cf. Fedi 2002: 116), y a su vez texto operativo (véase v. 56; Armisén, en prensa-a: texto y nn. 16 y 17) e integrado activamente desde su primer verso en la que he descrito (Armisén 2008: 49-51) como macrosecuencia de las enfermedades de Laura, apenas iniciada con el soneto XXXI. Hilos y tela, vida u obra ${ }^{13}$.

\footnotetext{
${ }^{13}$ No cabe descuidar la doble exégesis numérica de Agustín sobre la pesca milagrosa, dado que en Enarrationes, Ps. 150, 1 expresa su voluntad de solucionar mejor, cuando reciba la ayuda divina, el misterio numérico de los Psalmos. Su segunda lectura de la cifra de los 153 grandes peces la entiende marcada por la triplicación del $50,+3$ que lee como relacionada con la Trinidad. Sería así $50 x 3+3$. Ahí interpreta el 50 como resultado de 40+10. El 40 lo considera símbolo de la Iglesia presente. Con los 10 que se le suman, el 50 parece representar la Iglesia futura (In Iohannis evangelium. 122, 8; 123, 2; y
} 
Como ocurre con la colcha de Tetis y la escritura del carmen de Catulo, la fusión o -según advertía Julián Gállego (1984: 262-266) sobre el lienzo de Velázquez- la difícil, difusa distinción entre los "personajes vivos" situados ante el tapiz de "Las hilanderas" y los "ficticios" incorporados en su mismo tejido parece significativa. Más interesados hoy en los símbolos que identifican el discurso poético de Petrarca, atentos a los componentes constantes del continuum, recordemos ahí con las palabras de rima de la sextina doble el verso glosado por De Sanctis (1983 [1869, 1883]: 165 ss.) como característico de la situazione petrarchesca: «Et io son un di quei che 'l pianger giova», XXXVII, v. 69.

El misterioso soneto XL (según Santagata 1988: 58) merece, al menos, relectura atenta a tenor de la nueva información sobre macrocomposición secuencial y simbolismo reticular redentorista («tolse Giovanni da la rete et Piero») marcado desde la página inicial de los $R v f$ por el soneto IV. Un ordo presente ya en la forma o redazione Correggio que, se supone, situaba con esa misma disposición los primeros 120 pezzi por lo menos; y años más tarde forma potenciada, completando el proyecto modificado tras la muerte de Laura, por la presencia sostenida, intencional y cifrada del sistema numérico de Agustín (Gorni 1993: 124; Petrarca ed. 2004b: ccxccxi, Tavola I.; Savoca 2008: 86-89).

La construcción narrativa y la composición formal que el poeta concibe, hilvana y teje con el proyecto y programa del codice, cuya transcripción inició Malpaghini en octubre de 1366, genera repetidamente nuevas lecturas. Petrarca no pudo ignorar todas ellas y el texto de la redacción final del Secretum nos lo confirma desde fecha anterior. Lo que sabemos, con el reconocimiento añadido de las formas de composición numérica que estudio, lleva a pensar que en repetidos casos el poeta las buscó con intención y las controlaba con autoridad.

Pensemos también en el soneto CCLXVI del doble aniversario "Signor mio caro, ogni pensier mi tira", que comenté en un trabajo anterior como sencillo enigma cifrado (15+18), destinado a cerrar las rime in vitae. (Armisén 2011: 29-31; y en prensa-a). Su potenciación como homenaje a Giovanni Colonna con la incorporación en posición significativa de los $R v f$ se hace evidente. Reconocerlo ayuda a valorar la operación textual de Petrarca en la búsqueda de formas de macrocomposición del Canzoniere.

De modo que, si intentamos recuperar esas lecturas y los problemas de los lectores del siglo XVI y de fechas anteriores, hemos de mantener todavía, dado siquiera su interés histórico, la interpretación de la urdimbre textual e hilos del soneto XL como referida a la escritura de Petrarca. Solo, tal vez, a «una sua scrittura», según Leopardi [1826], pero también quizá y más directamente en la interpretación a la composición redentorista perceptible en los Rvf; o incluso, en algún caso, a la mo-

Enarrationes, Ps. 150, 1; cf. J. Oroz 1975: 452-453). No todos estos significados tienen el mismo interés. Advirtamos que, tras el soneto XL, la canción L "Ne la stagion che 'l ciel rapido inchina" es la que marca el décimo aniversario. Véase el comentario de Santagata (Petrarca ed. 2004b: 255-256). 
dular red simbólica que estudiamos en el libro de poesía vulgar. Durante mucho tiempo, entender este tejido referido en particular a los $R v f$ fue la lectura natural y más accesible a sus lectores e imitadores.

No creo que sea la sola razón para reivindicar esa lectura. Y tampoco soy el único. Al contrario que algún estudioso más interesado en el intento de fechar un temprano, difícil origen textual, sí entiendo verificables en el soneto XL tanto la creciente amenaza de Morte, activada en los $R v f$ con la recién abierta macrosecuencia de las enfermedades de 306 pezzi (XXXI-CCCXXXVI), como la constante influencia de Amor o la huella próxima del sistema numérico de Agustín que los acompaña en las formas de composición. Según veremos pronto, también podremos defender su reaparición última con la lectura agustiniana de la divina proportione que sacralizará después la paradoja de la muerte de Laura como solución cifrada de Divina Providencia (Armisén, en prensa-b).

\section{LOS HILOS DEL SONETO XL, CLAVE DE LA LECTURA MACROTEXTUAL DE MICHELANGELO PICONE. DE POSICIONES Y FORMA GRAFICO-VISIVA. EL TESSERE EN LA POESÍA DE SANNAZARO Y GARCILASO}

Aunque ajeno a las tesis que defiendo desde 2004 y 2008, Michelangelo Picone (2007a: 20-23 [2004: 91-93]) valora el interés del metaliterario soneto XL para una lectura de la trabajada composición macrotextual unitaria en la que su autor lo integra como tercer y último soneto del fol. 9, verso. Tal vez sea oportuno atender también, con la posición in ordine, a su localización grafico-visiva (estetica semantica, según Storey 2004: 132 ss.) en la paginación del codice ${ }^{14}$, página iniciada con los versos finales de la mencionada canción "Sì è debile il filo" y los sonetos XXXVIII y XXXIX dirigidos a interlocutores romanos.

Muy particular interés merece lo que reconocemos como admirable ejemplar (Armisén 1986: 226 ss.) ${ }^{15}$. La cifra numérica, al menos en los Rvf, confirma la in-

${ }^{14}$ No es caso único. Véase vv. 7-8 en sonetos IV y LXII; también CCXI, vv. 12-14, segundo en fol. 42, recto y CCCXXXVI, vv. 12-14, fol. 66, verso; y las peticiones in vita del CCXLVI, tercero en fol. 47 , recto, e in morte del CCCXLIX, fol. 58, recto. O el excepcional caso del v. 14 del soneto CCXIII en el cierre de fol. 42 recto. Reconocer en la forma del sonetto italiano de 154 sílabas -eficaz artefacto, breve máquina de significar posicionalmente (Geninasca 1976: 62-82)-, la condición de texto o forma básica fundamental de los $R v f$ unificado también con la misma ratio sesquitertia (88 / 66; 8 / 6 y 4 / 3), ayuda también a percibir el interés de otras posiciones recurrentes en la composición literaria y grafico-visiva del códice y sus 72 folios.

${ }^{15}$ Transcribo el comentario de Augustinus que en el Secretum precede a su profecía de la muerte de Laura y, en mi opinión, cumple ahí como justificación de las verdades útiles y de lo admirable ejemplar: «Ille quidem de anime immortalitate loquens opinionem pulcerriman omnium ac volens quam nichil in ea dubitaret quamque contrarium audire nollet ostendere, huiuscemodi verbis usus est; 
tencionalidad posicional del soneto de la data tragica (XXXI-CCCXXXVI) que culmina la centrada macrosecuencia de las enfermedades de Laura de 306 pezzi, y pauta la lectura modular con el pensamiento de Agustín y la huella de Providentia.

Según Agustín (De musica, I, 11, 18), el establecimiento de una ratio es la herramienta que, como dictus, hace finito el numerus que por naturaleza es inmutable e infinito (Correa Pabón 2009: 68). El alcance e implicaciones de esa conclusión no pueden pasar desapercibidos en la lectura de la composición (Agustín ed. 2008: 120).

La ratio 4:3 -marcada en el Canzoniere por la data sacra del soneto CCXI en el fol. 42 recto, según he advertido- había merecido el comentario de Agustín en De musica, I, 9 y 10; pero era materia tratada con más detalle en el De institutione musica de Boecio y en otros textos. De modo que Petrarca, por lo que conocemos, trabaja una sucesión numérica significada formalmente con la composición modular y secuencial ajustada con rationes conocidas (Armisén 2008: 58 ss., en prensa-b).

Tras el soneto IV que introdujo la figura de Laura con la redentorista rete evangélica (en posición final del fol. 1, recto que interesó a Amadi antes de 1563; también v. Savoca 2008: $34-36^{16}$ ), los trabajos textiles del XL serán, más adelante, tela de conflictos o incluso laberinto que, unido a la pretensión de Ícaro, puede requerir finalmente desde el CCXI de nueva Ariadna y nuevo Teseo. Y, antes también, literalmente opra d'aragna o ragnatela, con hipotéticos, significativos y discutidos antecedentes en el mito de Aracne (Metamorfosis, VI, vv. 1-145). Así en Rvf, soneto CLXXIII, v. 6 «quant'al mondo si tesse, opra d'aragna» (forma Chigi; y texto cuarto del fol. 36, recto, posición casi central en el total de 72 folios, Petrarca ed. 2004c; Gorni 1993: 137; Bettarini 1998: 137 y su Petrarca ed. 2005: 806).

Sobre los antecedentes del CLXXIII en Dante, la superbia de Aracne y el correlato de la envidia de Pallas (soneto CLXXII), véase el trabajo de Cherchi (2003: 140 ss.) Son también componentes caracterizados de la tentación de la superbia, propia de los poetas según el De musica (Agustín ed 1988: VI, 13, 40 ss.; y Armisén, en prensa-a: n. 2 y ss.), que hay que contrastar con la deseada o necesaria humilitas sobre la que he de volver.

tu in opinione fedissima atque falsissima iisdem verbis abuteris. Profecto enim etsi mortales esset anima, immortalem tamen extimare melius foret, errorque ille salutaris videri posset virtutis incutiens amorem; [...] contraque licet mendax venture vite promissio ad excitandum animos mortalium non ineficax videretur» (Secretum, III, 136). Por contigüidad inmediata queda referido al artificio post eventum, velado por la ambigüedad de la declaración del magíster sobre la temida muerte de Laura: «Equidem necessario eventura sunt» (Armisén, en prensa-a: texto y n. 12). Cito y numero el texto por la edición de Fenzi (Petrarca ed. 1992). La edición bilingüe de Rossend Arqués, siguiendo a Dotti, numera con otro criterio y libro por libro (Petrarca ed. 2011: 286-297). Sobre lo admirable ejemplar, v. Armisén (1986: 226 ss).

${ }^{16}$ Acerca del 4 Agustín habla en De musica, I, 12, 23 y I, 12, 25; sobre la tetractýs I, 12, 24; y sobre el 10 y la perfección en De musica, I, 11,29. Sobre las diferentes definiciones de ratio y proportio en Nicómaco, Agustín y Boecio, v. Correa Pabón (2009: 72 ss.). 
$\mathrm{Si}$ atendemos la relación de esa negativa ragnatela del soneto CLXXIII («Poi trovandol di dolce et d'amar pieno, / quant'al mondo si tesse, opra d'aragna / vede» ${ }^{17}$ (Iob, 8, 14; Ps. XXXVIII, 12; Is. 59, 5, cf. Santagata en Petrarca (ed. 2004b: 782); Marcozzi 2002: 233-235) con el anterior, muy próximo soneto CLXXI "Giunto m'à Amor fra belle et crude braccia" y la explícita referencia de sus sensuales ataduras a la desdeñosa, pétrea Anaxárete o donna petrosa (Petrarca ed. 2005: 799), el texto nos confirma su coherencia y la misma oportunidad excepcional. Podemos observar, con el precedente de Gorni (1993: 142), que esa ragnatela tiene también el posible antecedente de la sublimis aranea telam de Catulo, LXVIII, "Quod mihi fortuna", vv. 48-50 (según Gorni 1993: 142) ${ }^{18}$.

Una crisis superada in vita la de Francesco, al menos circunstancialmente, si hemos de valorar después los sonetos CCLXV o CCLXVI; y ahí la temporal, breve afirmación de su esperanza en el inicio de la Parte seconda, poco antes de conocer la muerte de Laura (Cherchi 2003: 143-145). Tras la inmediata desesperación post mortem (CCLXVIII), el proceso hacia la deseada recuperación de Laura y la confirmación final de la spes se reanuda.

Encontramos, así, la lectura plural y posicional de la escritura, construida pronto con ayuda de Agustín, en las imágenes simbólicas que se suceden, en los hilos sutiles (Psalmus CXVIII, 109-110; Enarrationes CXVIII, 23, 5-6 ${ }^{19}$ ) que construyen la vida del poeta (peregrinatio en ese mismo Salmo, de conocida forma criptoalfabética), en la búsqueda y la transformazione unitaria y redentorista.

Se realizará en las cadenas, nudos y lazos (o incluso redes: «veluti valida et robusta reste sua») (Psalmus CXVIII, 61; Enarrationes CXVIII, 16, 4; Secretum) que le retienen, tensiones en conflicto y formas discursivas que, cercanas al silencio, se funden aún con el llanto y el mito, acordes finalmente con la humilitas alcanzada y el

${ }^{17}$ Deyermond (1999: 74 ss.), aunque ajeno a Catulo y a los $R v f$ de Petrarca, advierte que los casos de Aracne, Philomela y Procne tienen en las Metamorfosis de Ovidio relación directa con el tema del tejido del texto como metáfora de la composición poética, más atento después a su presencia en escritores no latinos o en las secuencias y series narrativas de tapices vinculadas a La cárcel de Amor de Diego de San Pedro (¿1437-1498?).

${ }^{18} \mathrm{Si}$ en cuanto tela de araña destaca por su fragilidad, quizá también por su elaborada y mortal eficacia como red, en cuanto asociada a través del caso de Aracne con la soberbia castigada, puede tener otras implicaciones en relación amenazadora con la tentación reconocida de la gloria y con la aspiración de Petrarca a la difícil humilitas (Rico 1974: 130 ss.).

${ }^{19}$ Sobre el interés de Petrarca en el Psalmus CXVIII, v. Nolhac ([1892] 1965: II, 201) y Armisén (en prensa-a). El texto latino del Ps. CXVIII, v. 109 tiene, en ocasiones (con variantes en las traducciones que llegan vivas a algunas ediciones modernas y encuentro anotada en la Biblia comentada de Salamanca, IV Sapienciales (BAC, 1968, p. 620) una posible referencia a los hilos («Anima mea in manibus tuis semper»; «en la mano o en un hilo»). No la encuentro en el texto latino de la Vulgata y no es variante comentada por Agustín en Enarrationes CXVIII, 23, 4. Pero el tema del laqueus, explícito y desarrollado como tentación propuesta por pecadores ( Posuerunt peccatores laqueum mihi») en el inmediato v. 110 del Psalmus CXVIII, imagen que sí confirma la Vulgata, pudo ser leído como referido a ese mismo término. 
nombre recibido (lema anagramático del soneto I, v. 8; Armisén 2008: 65 y 68), finalmente clausurados. "Medusa et l'error mio m'àn fatto un sasso / d'umor vano stillante» (casi últimos vv. del fol. 72, recto; v. Marcozzi 2002: 255; Cherchi 2008: 172 ss.). La conflictiva dualidad ejemplificada con la alusión mítica final de la canción CCCLXVI, vv. 111 ss., sigue sorprendiendo a muchos lectores, pero ha sido antes componente sostenido y activo, perceptible en otros símbolos fundamentales.

Pese a todo lo publicado desde 1921 sobre el soneto "S'Amore o Morte non dà qualche stroppio / a la tela novella ch'ora ordisco" -Foresti, Billanovich, Santagata-, como numerosos lectores del XVI y siglos posteriores, Picone entiende válida en 2004 la identificación del padre Agustin que cree referida a la petición de una obra suya en este soneto XL, ayuda necesaria para la elaboración de un texto in progress: Triumphi, Rvf.. Es la misma propuesta, sin duda meditada, que después en 2007 se convertirá en aportación inicial, reiterada y fundamental de la reciente Lectura Petrarcae Turicensis (Picone 2007b: 292). La medida localización del soneto en la transcripción de 1366 completaba su función potencial con la composición del macrotexto, cerrado por el propio autor en 1374.

Como acabo de señalar, no es la única aproximación de Picone al soneto XL en esa colección de trabajos. En su aportación referida a los diez primeros sonetos del Canzoniere, comenta «L'iter ad Parnassum dell'io lirico (Rvf 6-10)» (Picone 2007c: 43-51; en particular 48 n. 47) y propone indirectamente la semejanza temática y funcional del mencionado XL "S'Amore o Morte" con el XCVI de la edizione vulgata de las Rime de Boccaccio "Tanto ciascun ad acquistar tesoro". Un soneto de petición en que el autor de la Amorosa visione, solicitaba ayuda para alcanzar sus metas literarias y espirituales. El soneto VII de Petrarca, puesto generalmente desde el siglo XVI en una supuesta relación con la poesía del de Certaldo hoy descuidada (Boccaccio ed. 1999 [1992]: 279, n. 1 y ss.), lleva a Picone en el 2007 a comentar los textos VII-X de los $R v f$ como unidos o centrados por el tema de las aspiraciones literarias de Petrarca, los mecenas, el problema de la Gloria y las ayudas necesarias.

No cabe descuidar la solicitud del soneto XL del de Arezzo, engastada con precisión formal como culto epigrama de petición en posición calculada -su inserción en los $R v f$ refuerza, potencia finalmente su discreta (y desenfadada, explícita) condición metatextual-, ajustada con el soneto IV de la creación figurada de Laura, tras los sonetos a Orso dell'Anguillara y a Giovanni Colonna. Ignorarla sería un nuevo error cuando reconocemos y valoramos la huella de Agustín en el componente moral, la composición narrativa y la trabajada textualidad unitaria intencional de los versos del Canzoniere.

Por el contrario, si desarrollamos alguna de las propuestas de lectura neopitagórica de 1563 que llevaron a Micer Anton Maria Amadi a presentar su amplia introducción sobre los números de la tétrada, pertinente en relación con la posición del soneto IV -hoy coincidente con la lectura visiva como rectángulo de la primera página (fol.1, recto) propuesta por Savoca en el 2008- la posición del soneto XL cobra mayor relevancia formal. Pensemos también en los De musica libri VI (y cf. 
mis nn. 4, 5 y 16). Creo que el soneto XL, tras el soneto IV que completó el fol. 1 recto del codice y justo ante el fol. 10 (Petrarca ed. 2004c), con su petición de los hilos necesarios reintroduce la suma de 10 con la potenciada tétrada. Petrarca apoya con las peticiones del soneto XL su aspiración a la forma acabada y la armonía. Al menos, sugiere una lectura posible, coherente y consecuente.

En una posición probablemente calculada, tras el soneto IV de la armónica, providencial creación de Laura y de la sagrada, primera red evangélica -precedido así mismo por el XXVI que introdujo la identificación del poeta como testor y permite considerar siquiera una sorprendente macrosecuencia de 306 pezzi (XXVICCCXXXII) sobre la escritura poética como tessere. El soneto XL como petición de ayuda, promesa de maravillas incluida, declara el interés del poeta en la escritura y sus trabajadas formas, establece el diálogo (invocatio) con un discretamente silenciado mecenas, de quien insinúa queja aún superable, y también expresa el reconocimiento de la deuda contraída con Agustín.

Lo significa y potencia en una posición de interés numérico con la declarada solicitud de ayuda y mediante la descripción simbólica del trabajo con la tela y los hilos. Una imagen clásica y bíblica que otros textos del Canzoniere recordarán después. Como el tema de la peregrinatio vitae -coincidentes ambos en el Psalmus CXVIII de interés reconocido por Nolhac en 1892-, apoya la intención espiritual y formal del poeta en la composición textual agustiniana de las rime sparse. Que en el siglo XVI esos hilos relacionados con alguna obra de Agustín generan lecturas reconocibles lo prueban espositiones de amplia difusión desde 1525 -o el canzoniere de Boscán (1543) en modo solo parcial-, y nos lo confirma la traducción castellana de Garcés que establece desde 1591 esa lectura en el mundo hispánico, amén de indicios varios y la imitación ocasional de otros poetas.

Volver sobre la opinión documentada de los que tuvieron acceso al codice d'autore parece todavía útil. Tampoco son los únicos datos que hay que valorar. Además de los posibles referentes bíblicos y clásicos de la imagen del Creador, del personaje mítico Amor de la leggiadra rete (Rvf, XXVI, CLXXXI, CCCXXXII) o del enamorado poeta con aspiración espiritual (sonetos [IV] y XL, sextina CCCXXXII) que trabajan su obra, como tela e hilos de un simbólico correlato objetivo conocido, el metaliterario motivo se establece tras el importante epilion de Catulo (écfrasis, ut pictura poesis). Siglos después, tanto la forma literaria del LXIV del veronés como la composición o la fabrica textual del Canzoniere se afirman en cuanto modelos de imitación.

Es una tradición rica, verificable en el siglo XVI con las labores de las ninfas de Sannazaro (Arcadia XII, 16) y que reaparece como cierre in cornice del De partu virginis (2009 [1526] Lib. III, vv. 499-513) en el marco napolitano de Mergellina, donde Federico d'Aragona (Napoli, 1452-Tours, 1504), Federico I di Napoli o IV d'Aragona le había donado una propiedad en 1497. Texto y espacio que, tras la muerte de Sannazaro en 1530, el Garcilaso desterrado llegado a Nápoles en 1532 tuvo que conocer muy pronto. 
La tela o tapiz y sus hilos los encontramos de nuevo en el soneto XI de Garcilaso de la Vega, "Hermosas ninfas, que en el río metidas", vv. 5-6; y localizadas en el toledano Tajo (Égloga II, v. 1243, v. Gargano 2009; y particularmente Égloga III, vv. 97-120). Para más información, véase la edición de Morros (Garcilaso de la Vega ed. 1995: 9, 26 y 518-519). Con otra intención y otros datos, alguno de esos poemas es forma revisada con brillante fruto en recientes ejercicios sobre el tejido del texto de Egido (2003: 186 ss.) y después por Maier-Troxler (2009: 87-95).

También la red y sus hilos son temas evocados en unas interesantes coplas octosilábicas castellanas: "De la red y del hilado", copla VI a doña Mencía de la Cerda que, según Morros advierte, tiene antecedentes varios en el Cancionero General. Ya sabemos que tampoco son los únicos ejemplos que hay que considerar. Bajo la influencia directa de los $R v f$ (recordemos la precisa nota de Prieto (Petrarca ed. 1985: 134) al importante soneto CLXXXI de Petrarca "Amor fra l'erbe una leggiadra rete"), lo trata Garcilaso -víctima él mismo enredada en la pasión amorosa como antes lo fueron Venus y Marte en la red de Vulcano- en su Canción IV: «de los cabellos de oro fue tejida / la red que fabricó mi sentimiento, / do mi razón, revuelta y enredada», vv. 101-107. Contrástese la mencionada propuesta de Prieto, hoy muy útil, con las de Morros (Garcilaso de la Vega ed. 1995: 76 y 81) y Egido (2003: 186). No insistiré en la interpretación de la parodia quijotesca de 1615 (Quijote, II, LVIII) que ya he anotado inicialmente por su relación con el Canzoniere.

Interesa reconocer así mismo el uso particular que Petrarca hace de la metafora di testo (la metáfora textil de la Creación) en la construcción y lectura unitaria de los Rvf, pero el soneto XL hace además explícita la trabajada relación de sus nugae con la obra y el pensamiento de Agustín a través de símbolos cardinales. Y si los poetas clásicos proponent, invocant, narrant, el soneto XL, en la nueva forma de libro de poesía del codice Vat. lat. 3195, es un texto con valor simbólico funcional importante. Lo entiendo apoyado numérica y posicionalmente. Es momento caracterizado del continuum (textus, fabrica) que, tras anteriores menciones a las ayudas necesarias y mecenas (Picone 2007c: 43ss), todavía actualiza con énfasis una forma reconocible de plural invocatio en los Rvf.

La imagen telar de la creación, de la vida y la escritura, marcada por el textus, el tessere y sus hilos como supieron pronto lectores de Dante y Petrarca, era motivo temático anterior relacionado ya con el laberinto de Minos en la Eneida (Virgilio, ed. 1986: V, vv. 588-590) y con la composición necesaria (Quintiliano, Institutio oratoria, IX, iv, 13), con antecedentes e innumerables ecos en textos sagrados y profanos.

Si bien tenía entonces el muy lejano, dispar y conocido precedente homérico o el caso silencioso de Filomela, la imagen llegará aún viva, con cifra numérica biográfica, en «un abecedario ceniciento» (Psal. CXVIII) -como umbilical y bíblico, clásico hilo de Ariadna: maternal devanar, hogareño y elegíaco, regresivo y reivindicativo- hasta la poesía realista del siglo XX en «Biotz-Begietan» de Blas de Otero (Armisén 2010b: 13-14). 


\section{REFERENCIAS BIBLIOGRÁFICAS}

Para la localización de estudios petrarquistas mencionados de forma ocasional, remito regularmente a la bibliografía de la edición del Canzoniere de M. Santagata (Petrarca ed. 2004b), edición de referencia por la que cito. En el caso de los distintos estadios y recolecciones de los $R v f$ hago uso, como en trabajos anteriores, de la información y siglas (Co., Ch., $\mathrm{Pr}$, Pm3, Pm4, etc.) de esa misma edición, Introduzione, Le Redazioni, pp. ccv-ccxvi.

Agustín DE HIPONA (ed. 1954-1957): Enarrationes in Psalmos, Obras de San Agustín, ed. bilingüe de B. Martín Pérez, Madrid, BAC, vols. XIX-XXII, Agustín DE HIPONA (ed. 1958): Tractatus in Iohannis Evangelium, Obras de San Agustín, ed. bilingüe y trad. de V. Rabanal, Madrid, BAC, vol. XIV.

Agustín DE HIPONA (ed. 1988): De musica libri VI, Obras completas de San Agustín, vol. XXXIX, Escritos varios I, ed. bilingüe de A. Ortega, Madrid, BAC, pp. 65-361.

Agustín DE HIPONA (ed. 1992 [1976]): De Musica Libri VI, trad. italiana de D. Gentili, Piacenza, Nuova Editrice. Hay ed. electrónica en Nuova Biblioteca Agostiniana $<$ www.augustinus.it $>>$

Agustín DE HIPONA (ed. 2000): De civitate Dei, Obras completas de San Agustín, ed. bilingüe y trad. de S. Santamarta del Río y M. Fuertes Lanero; introd. y notas de V. Capanaga, Madrid, BAC, vols. XVI y XVII.

Agustín DE Hipona (ed. 2008): Sobre la música. Seis libros, trad., introd. y notas de J. Luque Moreno y A. López Eisman, Madrid, Gredos.

Alonso, Dámaso (1972): Obras completas, Madrid, Gredos, vol. III, pp. 768-769.

AMADI, Anton Maria (1563): Ragionamento di m. anton maria amadi intorno quel sonetto che incomincia "Quel che infinita providentia et arte»..., in Padova apresso Gratioso Percacino. [Ejemplar de la Biblioteca Apostolica Vaticana R.I. IV, 1475 int. 1].

AMATURO, Raffaele (1988 [1971]): Petrarca, Bari, Laterza

ARMiséN, Antonio (1982): Estudios sobre la lengua poética de Boscán. La edición de1543, Zaragoza, Libros Pórtico/Universidad de Zaragoza.

ARMISÉN, Antonio (1986): «Admiración y maravillas en El Criticón (más unas notas cervantinas)», en AA.VV., Gracián y su época. Actas de la I Reunión de Filólogos Aragoneses, Zaragoza, Institución Fernando el Católico, pp. 201-242.

ARMISÉN, Antonio (1999): Jugar y leer. El Verbo hecho tango de Jaime Gil de Biedma, Zaragoza, Prensas Universitarias de Zaragoza.

ARMISÉN, Antonio (2004a): «Composición numérica e imitación. El 153 de la pesca milagrosa, la exégesis de Agustín y su huella en Petrarca y Boscán», Cuadernos de Filología Italiana 11, pp. 75-98.

ARMiSÉN, Antonio (2004b): «Sobre el 153 y la Piazza di San Pietro di Roma. Bernini y la numerología jesuítica. El caso Gracián», Boletín Museo e Instituto Camón Aznar XCIV, pp. 65-101.

ARMISÉN, Antonio (2008): «Sobre la composición del Canzoniere (codice Vat. lat. 
3195): sistema de peticiones, macrosecuencias y sesquitertia ratio», Cuadernos de Filología Italiana 15, pp. 47-72.

ARMISÉN, Antonio (2010a): «Garcilaso y el verso travestido de Altisidora. Anaxárete, Dido, Avellaneda y la escritura meliorativa del Quijote de $1615 »$, en $\mathrm{M}^{\mathrm{a}} \mathrm{C}$. Marín Pina (coord.), Cervantes en el espejo del tiempo, Zaragoza, Servicio de publicaciones de la Universidad de Alcalá/Prensas Universitarias de Zaragoza, pp. 15-60.

ARMISÉN, Antonio (2010b): «Cifra formal y dodecasílabo asimétrico en la poesía de los 50. A propósito de los versos partidos en el edición crítica (2009) de J. Agustín Goytisolo», Pensamiento literario español del siglo XX 4, pp. 7-30.

ARMISÉN, Antonio (2011): «Composición secuencial y lectura numérica (texto literario y códice de autor) en los Rerum vulgarium fragmenta: el sistema de aniversarios y sus incongruencias», Perusia 7, pp. 9-40.

ARMiSÉN, Antonio (en prensa-a): «Posiciones, causas y razones en los Rvf: 1.- Voluntad de acabar y Spes en los sonetti CCXLVI y CCCXLIX. La vaticinatio post eventum de Augustinus», Tropelías 19.

ARMISÉN, Antonio (en prensa-b): «Posiciones, causas y razones en los Rvf: 2.- Sobre los casos particulares del 2004. Muerte de Laura, Providentia y divina proportione», Tropelías 20.

BEC, Pierre (1977): La lyrique française au Moyen Age (XII-XIII siècles): contribution à une typologie des genres poétiques médiévaux, I: Études, Paris, A. \& J. Picard.

BERRA, Claudia (1991): «La sestina doppia CCCXXXII», Lectura Petrarce, XI, pp. 219-235.

BetTARIni, Rosanna (1998): Lacrime e inchiostro nel Canzoniere di Petrarca, Bologna, Clueb.

BillanOVICH, Giuseppe (1996): Petrarca e il primo umanesimo, Padova, Antenore.

BIBLIA vulgata, ed. de A. Colunga y L. Turrado, Madrid, BAC, 1965.

BoCCACCIO, Giovanni (ed. 1992): Rime, a cura di V. Branca, Milano, Mondadori.

BolognA, Corrado (2007): «Occhi, solo occhi (Rvf 70-75)», en M. Picone (ed.), Lectura Petrarcae Turicensis, Il Canzoniere. Lettura micro e macrotestuale Ravenna, Longo Editore, pp. 183-206.

Catulo, Gayo Valerio (2006): Poesías, edición bilingüe de J. C. Fernández Corte y J. A. González Iglesias, Madrid, Cátedra.

Cervantes, Miguel de (ed. 1998): Don Quijote de la Mancha, edición dirigida por F. Rico, Madrid, Instituto Cervantes/Crítica, $2^{\mathrm{a}}$ ed. corregida, 2 vols.

CHERCHI, Paolo (2003): «Opra d'aragna (Rvf CLXXIII)» en J. Bartuschat y L. Rossi (eds.), Studi sul canone letterario del Trecento. Per Michelangelo Picone, Ravenna, Longo, pp. 135-145.

Cherchi, Paolo (2008): Verso la chiusura. Saggio sul Canzoniere di Petrarca, Bologna, Il Mulino. 
Chessa, Silvia (2005): Il profumo del sacro nel Canzoniere di Petrarca, Firenze, Società Editrice Fiorentina

CORREA PABÓN, Guillermo León (2009): Numerus-Proportio en el De musica de san Agustín (Libros I y VI). La tradición pitagórica y platónica. Tesis doctoral inédita. Universidad de Salamanca.

CRESPO, Patricia (2001): «Las costuras narrativas del Quijote: la metáfora textil en la construcción de la novela», Bulletin of Hispanic Studies LXXVIII, pp. 567575.

De SAnCTIS, Francesco (1983 [1869, 1883]): Saggio critico sul Petrarca, a cura di N. Gallo; introduzione di N. Sapegno, Torino, Einaudi.

DEYERMOND, Alan (2001[1999]): «El tejido en el texto, el texto tejido: las chansons de toile y poemas análogos», en F. Carmona y A. Martínez (eds.), Géneros literarios e interrelaciones de géneros en la literatura medieval (= Estudios Románicos 11), pp. 71-104.

DotTi, Ugo (1987): Vita di Petrarca, Roma/Bari, Laterza.

EGIDO, Aurora (2003): «El tejido del texto en la Égloga III de Garcilaso», en J.M. Díez-Borque y L. Ribot García (eds.), Garcilaso y su época: del amor y la guerra, Madrid, Sociedad Estatal de Conmemoraciones Culturales, pp. 179-200.

Foster HOPPER, Vincent (1978 [1938]): Medieval Number Symbolism, Pennsylvania, Norwood.

FrASCA, Gabriele (1992): La furia della sintassi. La sestina in Italia, Napoli, Bibliopolis.

GÁLLEGO, Julián (1984): Visión y símbolos en la pintura española del siglo de Oro, Madrid, Cátedra

Gargano, Antonio (2009): «L'Arcadia di Sannazaro in Spagna: l'Egloga II di Garcilaso tra Imitatio e modello bucolico» en P. Sabbatino (ed.), Jacopo Sannazaro. La cultura napolitana nell'Europa del Rinascimento, Firenze, Leo S. Olschki, pp. 287-296.

GENINASCA, Jean (1976): «Fragmentación convencional y significación», en A. J. Greimas et al., Ensayos de semiótica poética, Barcelona, Planeta, pp. 62-82.

GORNI, Guglielmo ([1979] 1993): «La metafora di testo», Metrica e analisi letteraria, Bologna, Il Mulino, pp. 137-152.

HERNÁNDEZ ESTEBAN, María (2001 [1987]): «Procedimientos compositivos de la sestina. De Arnaut Daniel a Fernando de Herrera», Revista de Literatura XLIX (98), pp. 351-424. Reimpreso en M. Hernández Esteban, El Texto en el Texto. Lecturas de géneros literarios, Universidad de Málaga, pp. 125-201.

HERrera, Fernando de (ed. 1985): Poesía castellana original completa, ed. de C. Cuevas, Madrid, Cátedra.

LUQUE MORENO, Jesús (2001): «Numerus: la articulación rítmica del lenguaje», en A. Alvar Ezquerra y F. García Jurado, Actas del X Congreso Español de Estudios Clásicos, Madrid, Sociedad Española de Estudios Clásicos/Ediciones Clásicas, pp. 493-530. 
MACRoBIo, Ambrosio Teodosio (ed. 1981): Comentariorum in somnium Scipionis Libri Duo, introduzione, testo, traduzione e note a cura di L. Scarpa, Padova, Liviana Editrice.

MACROBIO, Ambrosio Teodosio (ed. 2001): Commentaire au Songe de Scipion, texte établi, traduit et commenté par M. Armisen-Marchetti, Paris, Les Belles Lettres, Livre I.

MACROBIO, Ambrosio Teodosio (ed. 2006): Comentario al Sueño de Escipión de Cicerón, introducción, traducción y notas de F. Navarro Antolín, Madrid, Gredos.

MAIER-TROXLER, Katharina (2009): «Alegrando la vista y el oído: tejido y texto en la 'Égloga III' de Garcilaso», en M. Burkhardt, A. Plattner y A. Schorderet, Parallelismen / Parallèlismes / Paralelismos: Literatur -und Kulturwissensschaftliche Beiträge zu Ehren von Peter Fröhlicher, Tübingen, Narr / Francke / Attempto, pp. 87-95.

MARCOZZI, Luca (2002): La Biblioteca di Febo. Mitologia e Allegoria in Petrarca, Firenze, Cesati Editore.

MARTíNEZ VÉLEZ, Pedro (1931): El número agustiniano. Contribución al estudio de la filosofia de San Agustín, El Escorial, Imprenta del Monasterio.

NolHaC, Pierre de (1965 [1892]): Pétrarque et l'humanisme, 2 vols., Paris, Librairie Honoré Champion.

OrOZ, José (1975): «De Pitágoras a san Agustín: Realidad y simbolismo de los números», Helmantica 26 (79-81), pp. 427-453.

OtaOla, Paloma (2005): El De musica de Agustín y la tradición pitagóricoplatónica, Valladolid, Estudio Agustiniano.

OviDIO, Publio (1984): Metamorfosis, revisión y trad. de A. Ruiz de Elvira, Madrid, Consejo Superior de Investigaciones Científicas, 3 vols.

OXFORD LATIN DICTIONARY (ed. 1990), ed. de P.G.W. Glare, Oxford, Clarendon Press.

Pastore StocchI, Manlio (1981): «I sonetti III e LXI», Lectura Petrarce I, pp. 171-191.

PelosinI, Raffaella (1998): «Il sistema-sestine nel Canzoniere (e altre isotopie di Laura)», Critica del testo V, pp. 665-721

Petrarca, Francesco (ed. 1525 y 1538): Le Opere Volgari del Petrarcha con la espositione di Alessandro Vellutello da Lucca, Venezia. $<$ http://books.google.com>.

PetraRCA, Francesco (ed. 1984 [1899]): Le Rime, a cura de Giosuè Carducci e Severino Ferrari, reeditada con prólogo de G. Contini, Firenze, Sansoni.

PetrarCA, Francesco (ed. 1985): Cancionero, ed. de la traducción castellana de Enrique Garcés (Madrid, Drouy, 1591) con ensayo introductorio y notas de A. Prieto; cronología y bibliografía de M. Hernández Esteban. Barcelona, Planeta.

PETRARCA, Francesco (ed. 1992): Secretum / Il mio segreto, edizione commentata bilingue a cura di E. Fenzi, Milano, Mursia.

Petrarca, Francesco (2003): Canzoniere, introduzione di Ugo Foscolo, note di Giacomo Leopardi, a cura di U. Dotti, Milano, Feltrinelli. 
Petrarca, Francesco (ed. 2004a [1996]): Canzoniere, a cura di U. Dotti, Roma, Donzelli Editore, 2 vols.

PetrarCA, Francesco (ed. 2004b [1996]): Canzoniere, edizione comentata a cura di M. Santagata, Milano, Mondadori.

PetrarCA, Francesco (ed. 2004c [1904]): Rerum vulgarium fragmenta. Codice Vat. lat. 3195. Commentario all'edizione in fac-simile, edizione diplomatica di Ettore Modigliani, a cura di G. Belloni, F. Brugnolo, H. W. Storey e S. Zamponi, Ro$\mathrm{ma} /$ Padova, Editrice Antenore.

PetrarcA, Francesco (ed. 2005): Canzoniere. Rerum vulgarium fragmenta a cura di R. Bettarini, Torino, Giulio Einaudi Editore, 2 vols.

PetrarcA, Francesco (ed. 2008): Rerum vulgarium fragmenta, edizione critica di G. Savoca, Firenze, Leo S. Olschki Editore.

PetrarcA, Francesco (ed. 2011): Mi secreto/Epistolas, ed. bilingüe de R. Arqués Corominas, Madrid, Cátedra.

PICONE, Michelangelo (2007a [2004]): «Petrarca e il libro non finito», en Petrarca volgare (= Italianistica, XXXIII/2, pp. 83-93); reimpreso en M. Picone (ed.), Lectura Petrarcae Turicensis. Il Canzoniere Lettura micro e macrotestuale, Ravenna, Longo Editore, pp. 9-23.

PICONE, Michelangelo (2007b): «Amor e Gloria nella composizione di RVF 110-19 en M. Picone (ed.), Lectura Petrarcae Turicensis. Il Canzoniere Lettura micro e macrotestuale, Ravenna, Longo Editore, pp. 279-294.

PICONE, Michelangelo (2007c): «L'inizio della storia (RVF 1-10)», en M. Picone (ed.), Lectura Petrarcae Turicensis. Il Canzoniere. Lettura micro e macrotestuale, Ravenna, Longo Editore, pp. 25-51.

PiCone, Michelangelo (ed.) (2007): Lectura Petrarcae Turicensis. Il Canzoniere. Lettura micro e macrotestuale, Ravenna, Longo Editore.

QueVEDO, Francisco de (1981): Poesía original completa, ed. de J. M. Blecua, Barcelona, Planeta.

QUinTILIANO, Marco Fabio (ed. 1979): Institutio oratoria, with an English translation by H. E. Butler, London, Harvard University Press/W.Heinemann/ Loeb Classical Library, 4 vols.

RICO, Francisco (1974): Vida y obra de Petrarca. I. Lectura del Secretum, Padova, Editrice Antenore.

RøSTVIG, Maren-Sofie(1970): «Structure as prophecy: the influence of biblical exegesis upon theories of literary structure», en A. Fowler (ed.), Silent Poetry, London, Routledge and Kegan Paul, pp. 32-72.

SANNAZARO, Jacopo (2009): Latin Poetry, bilingual edition, translated by Michael C. J. Putnam, Cambridge (Mass.)/London, The I Tatti Renaissance Library/ Harvard University Press.

Santagata, Marco (1988): Petrarca e i Colonna. Sui destinatari di R.v.f. 7, 10, 28 e 40, Lucca, Maria Pazzini Fazzi editore 
Santagata, Marco (1990): Per moderne carte. La biblioteca volgare di Petrarca, Bologna, Il Mulino.

SAPEGNO, Maria Serena (1999): Petrarca e lo stile della Poesia, Roma, Bagatto Libri.

SAVocA, Giuseppe (2008): Il Canzoniere di Petrarca tra codicologia ed ecdotica, Firenze, Leo S. Olschki.

SoldANI, Arnaldo (2007a): «Voce e temporalità nella narrazione del Canzoniere», en AA. VV., Studi in onore di Pier Vicenzo Mengaldo per i suoi settant'anni, Firenze, SISMEL/Ed. del Galluzzo, vol. I, pp.325-345.

SoldANI, Arnaldo (2007b): «Dialoghi e soliloqui al limitare del tempo ( $R v f 351$ 59)», en M. Picone (ed.), Lectura Petrarcae Turicensis. Il Canzoniere Lettura micro e macrotestuale, Ravenna, Longo Editore, pp. 759-798.

STOREY, H. Wayne (2004): «All'interno della poetica grafico-visiva di Petrarca», en F. Petrarca, Rerum vulgarium fragmenta. Codice Vat lat 3195. Commentario, a cura di Gino Belloni, Furio Brugnolo, H. Wayne Storey e Stefano Zamponi, Roma/Padova, Editrice Antenore, pp. 131-171.

STIERLE, Karl (1996): «Il sonetto CCCLIII», Lectura Petrarce XVI, pp. 231-247.

Stroppa, S. (2004): "'Obscuratus est sol'. Codice lirico e codice biblico in Rvf III», Lettere Italiane LVI/2, pp.165-189.

VEGA, Félix Lope de (1983): Obras poéticas, edición, introducción y notas de J. M. Blecua, Barcelona, Planeta.

VEGA, Garcilaso de la (ed. 1995): Obra poética y textos en prosa, ed., prólogo y notas de B. Morros, Barcelona, Crítica.

VIlJAMAA, Toivo (2007): “'Text' as 'hyphos' in Quintilian (Institutio oratoria 9.4.3, 3-23)», en O. Merisalo y R. Vainio (eds.), Ad itum liberum: Essays in honour of Anne Helttula, Jyväskylä, Jyväskylä University, pp. 131-138.

VIRGILIO, Publio (1982): La Eneida, trad. de R. Hernández de Velasco (1555); introd. y notas de V. Bejarano, Barcelona, Planeta.

VIRGILIO, Publio (1986) Aeneid, with an English translation by H. Rushton Fairclough, London, Harvard University Press/W. Heinemann Ltd/ Loeb Clasical Library, 2 vols.

ZAMPONI, Stefano (2004): «Il libro del Canzoniere: modelli, strutture, funzioni», en F. Petrarca, Rerum vulgarium fragmenta. Codice Vat .lat 3195. Commentario, a cura di G. Belloni, F. Brugnolo, H. W. Storey e S. Zamponi, Roma/Padova, Editrice Antenore, pp. 13-72.

ZENARI, Massimo (2001): «Sulle figure della annominatio comprese nei repertori metrici. Il 'Canzoniere' di Francesco Petrarca», Studi Petrarcheschi XIV, pp.1-113. ZINK, Michel (1978): Belle. Essai sur les chansons de toile, Paris, Honoré Champion. 